2017-12-01

\title{
An Examination of the Factor Structure of the Trauma Inventory for Partners of Sex Addicts (TIPSA)
}

Heidi A. Vogeler

Brigham Young University

Follow this and additional works at: https://scholarsarchive.byu.edu/etd

Part of the Educational Assessment, Evaluation, and Research Commons

\section{BYU ScholarsArchive Citation}

Vogeler, Heidi A., "An Examination of the Factor Structure of the Trauma Inventory for Partners of Sex Addicts (TIPSA)" (2017). All Theses and Dissertations. 6654.

https://scholarsarchive.byu.edu/etd/6654 
An Examination of the Factor Structure of the Trauma Inventory for Partners of Sex Addicts (TIPSA)

Heidi A. Vogeler

A dissertation submitted to the faculty of Brigham Young University

in partial fulfillment of the requirements for the degree of

Doctor of Philosophy

\author{
Lane Fischer, Chair \\ Melissa Heath \\ Aaron Jackson \\ Joseph Olsen \\ Richard Sudweeks
}

Educational Inquiry, Measurement, and Evaluation

Brigham Young University

Copyright (C) 2017 Heidi A. Vogeler

All Rights Reserved 


\section{ABSTRACT \\ An Examination of the Factor Structure of the Trauma Inventory for Partners of Sex Addicts (TIPSA) \\ Heidi A. Vogeler \\ Educational Inquiry, Measurement, and Evaluation, BYU \\ Doctor of Philosophy}

The primary purpose of this study was to examine the underlying latent factor structure of the Trauma Inventory for Partners of Sex Addicts (TIPSA), a 53-item assessment designed to assess for Post-Traumatic Stress Disorder (PTSD) in the context of sexual addiction. It was theorized that the factor structure mirrored the 5 core criteria for PTSD as constituted in DSM-5. Data were gathered from 3,199 self-selected respondents (ages 21 to 55) who completed an online version of the TIPSA.

Confirmatory Factor Analysis (CFA) was performed utilizing Mplus in order to confirm the hypothesized factor structure of the TIPSA. Several modifications were made to the model, based on factor loadings and modification indices, in order to improve goodness-of-fit. In addition to the original posited model, three other models were also examined: a second-order factor model; a general-factor model; and a bifactor model. The second-order factor model emerged as the model of choice, based on both statistical and theoretical underpinnings.

As a result of the findings from this study, revision of the items contained in the TIPSA is recommended. In addition, in order to further establish the validity of the TIPSA as an assessment for PTSD, evaluating convergent and discriminant validity of the TIPSA with other established assessments, such as the National Institutes of Mental Health (NIMH) PTSD Checklist, is also suggested.

Keywords: addictive behavior, factor analysis, trauma 


\section{ACKNOWLEDGEMENTS}

Just as it takes a village to raise a child, it takes an army to defend a dissertation. There is no way to thank everyone that could or should be thanked. However, there are a few who deserve to be acknowledged in writing. First, Eric Vogeler and Zach Lifferth for reading and editing a document totally unrelated to their expertise. Next, Sara Moulton and Brian Jones for allowing me to pick their brains at random moments in the lab, and Steve Stokes who wrote a magnificent dissertation that took a significant load off my shoulders. I also want to thank Ross Larsen for lending his expertise and providing confidence-boosting feedback.

Finally, I am very grateful to my committee for their support - especially Drs. Fischer and Sudweeks. Thank you to Dr. Sudweeks for his in-depth thought and research on behalf of this project, and for always asking questions and posing concerns that helped solidify the final product. And last, but not least, Dr. Fischer for his steadiness and reassurance that a crazy

graduate student, such as myself, really can do the impossible. Thank you for being my guide on this journey. One down, one to go! 


\section{TABLE OF CONTENTS}

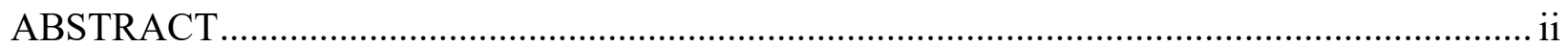

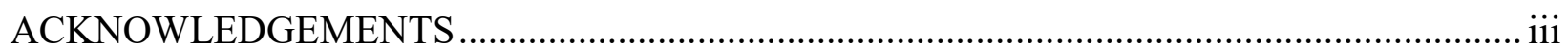

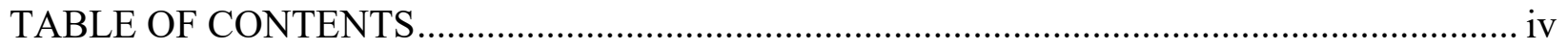

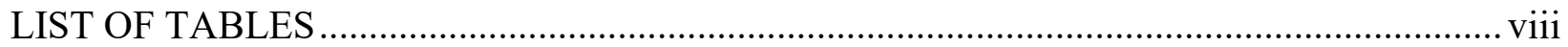

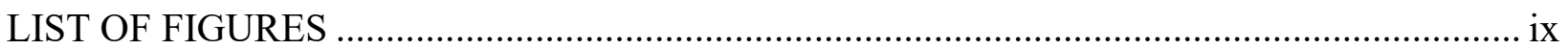

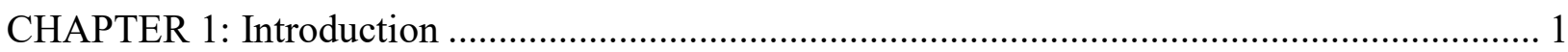

The Experience of Partners of Sex Addicts .................................................................. 1

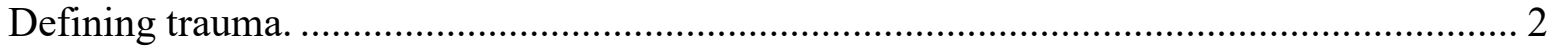

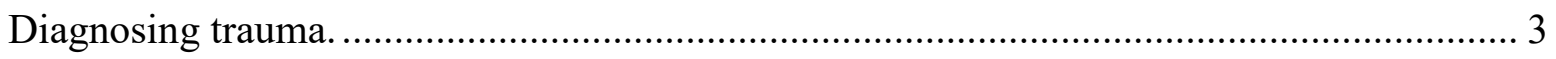

Treating Partners of Sex Addicts ............................................................................... 4

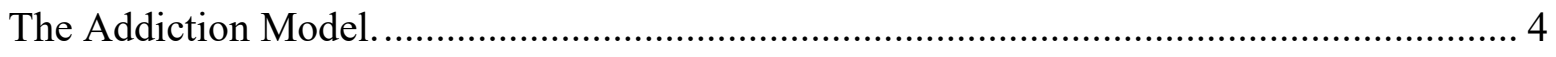

The Trauma Model …................................................................................................... 5

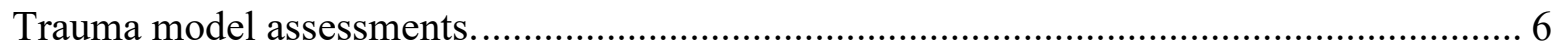

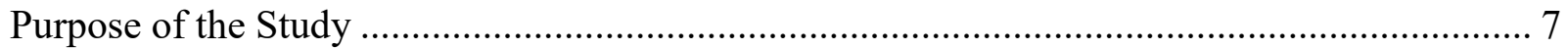

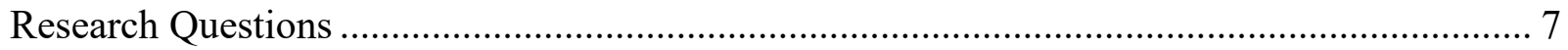

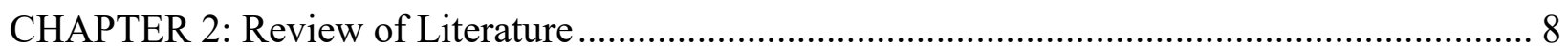

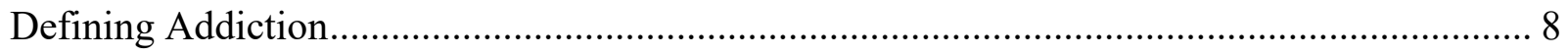

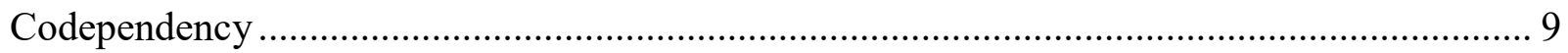

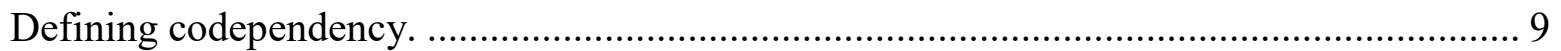




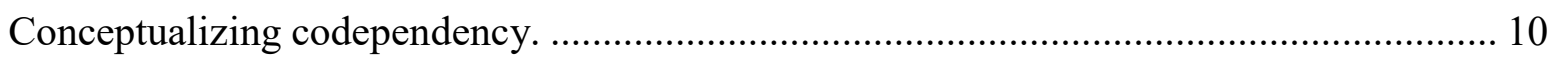

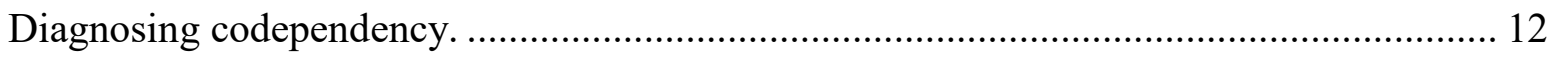

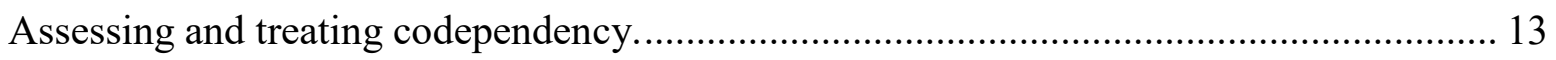

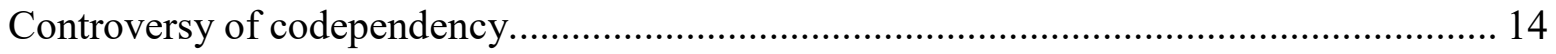

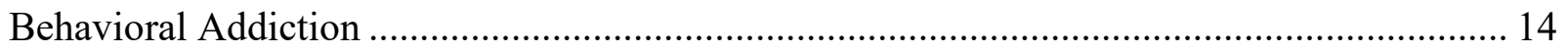

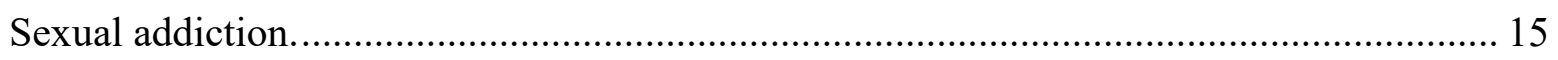

Codependency and sexual addiction............................................................................ 16

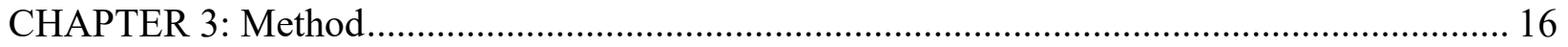

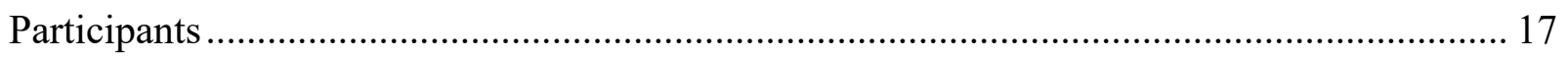

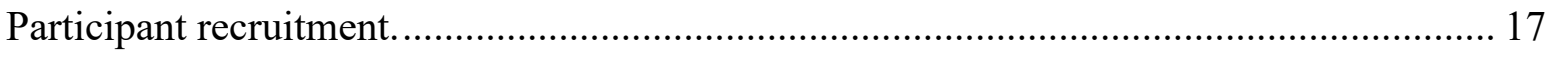

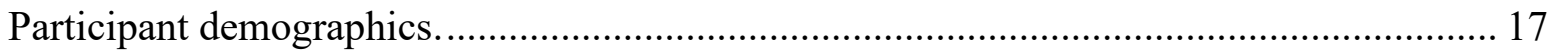

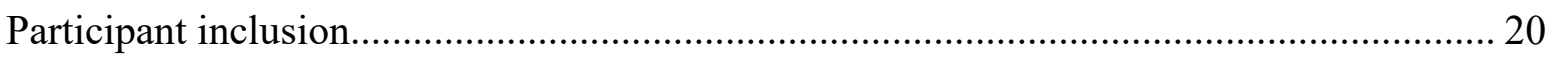

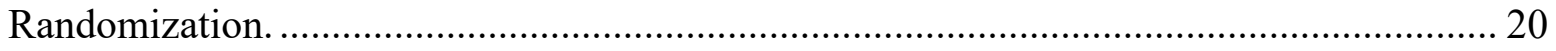

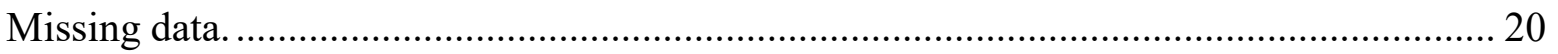

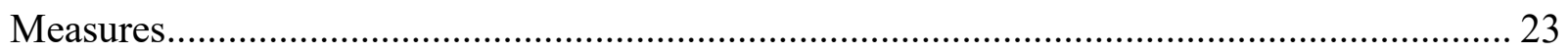

The Trauma Inventory for Partners of Sex Addicts (TIPSA) 2.0 ……………………...... 24

The Trauma Inventory for Partners of Sex Addicts (TIPSA) 2.1 ...................................... 24

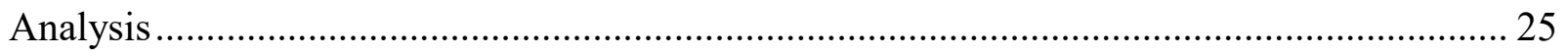

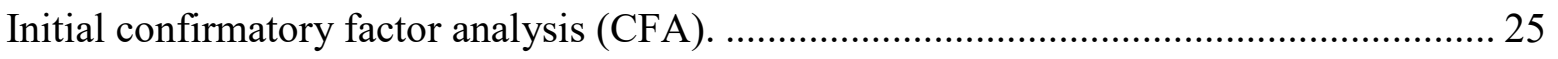

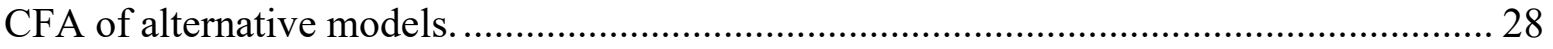

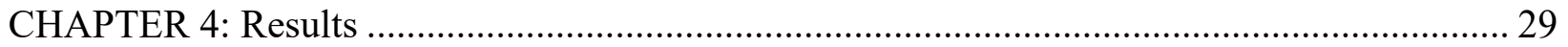




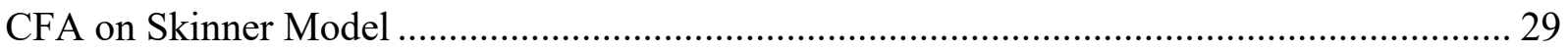

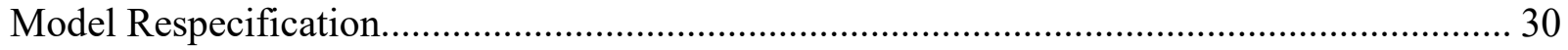

Model modification utilizing ON/BY statements .................................................. 31

Modification utilizing WITH statements............................................................... 32

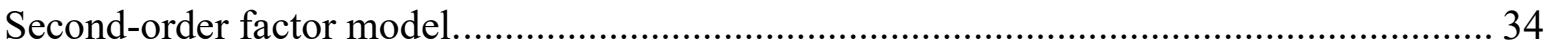

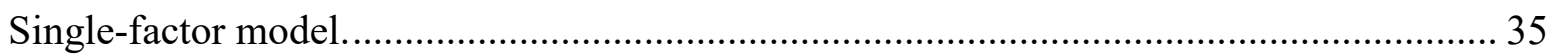

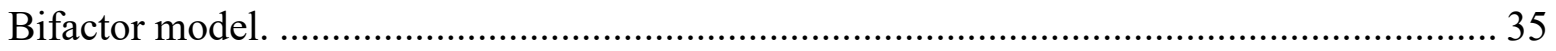

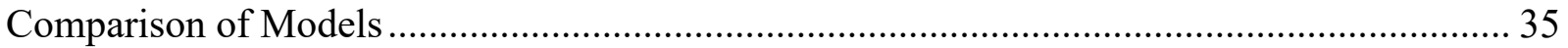

CFA of Models Using Collapsed Category Data ............................................................. 40

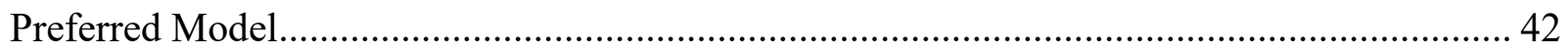

Cross-validation of Second-order Factor Model .......................................................... 46

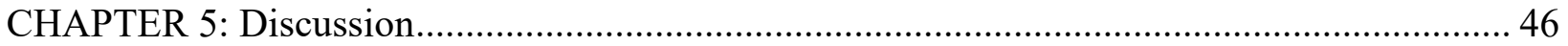

The Second-order Factor Model .................................................................................. 46

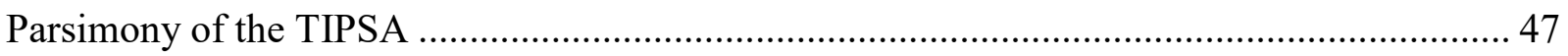

Recommendations for Revision of the TIPSA ............................................................. 48

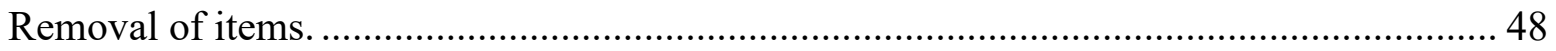

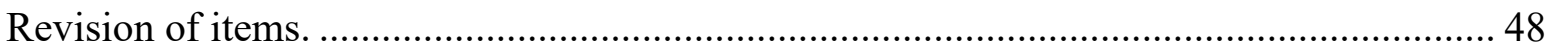

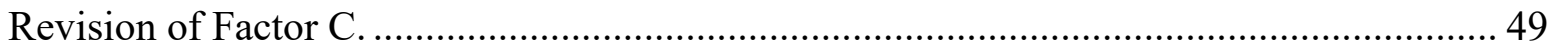

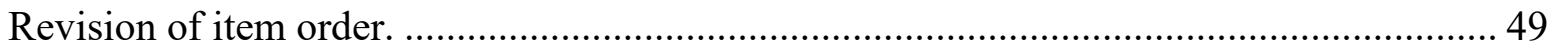

Original versus collapsed response categories..................................................... 50

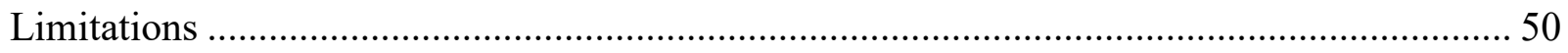


Suggestions for Future Research............................................................................. 51

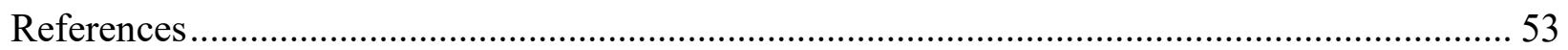

APPENDIX A Trauma Inventory for Partners of Sex Addicts (TIPSA).................................. 61 


\section{LIST OF TABLES}

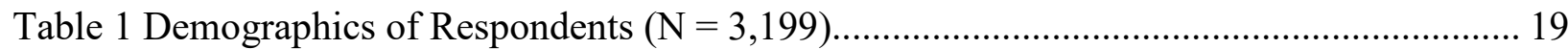

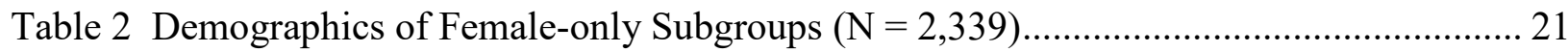

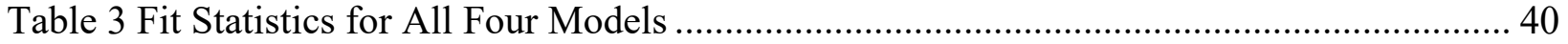

Table 4 DIFFTEST Results of 5-factor Model Compared to

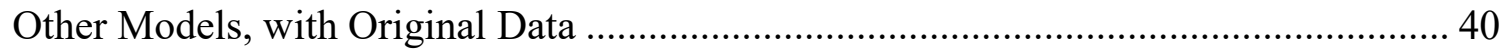

Table 5 Item Rescoring (Collapsed Response Categories) ............................................... 41

Table 6 Fit Statistics for All Four Models with Rescored Data (without Item 32) ................... 42

Table 7 DIFFTEST Results of 5-factor Model Compared to

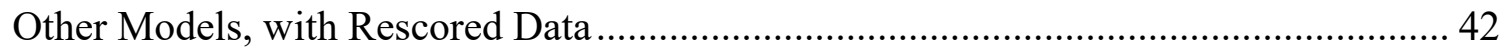

Table 8 Cross-validation Fit Criteria Comparisons for Second-order Model............................ 46 


\section{LIST OF FIGURES}

Figure 1. 5-factor Model with original data........................................................................ 36

Figure 2. Second-order Factor Model with original data................................................. 37

Figure 3. Single General-factor Model with original data ................................................ 38

Figure 4. Bifactor Model with original data. ............................................................... 39

Figure 5. 5-factor Model with rescored data...................................................................... 43

Figure 6. Second-order Factor Model with rescored data................................................... 44

Figure 7. Single General-factor Model with rescored data order factors. ................................ 45 


\section{CHAPTER 1}

\section{Introduction}

Codependency has slowly become a permanent fixture in psychological, psychiatric, and addiction literature (Minwalla, 2012; Stafford, 2001). Originally, the term codependent referred to family members who were unable to objectively view the nature of substance abuse disorders and who consequently adapted their behaviors in ways that facilitated the continued substance use and abuse (Cermak, 1991; Sarkar, Mattoo, Basu, \& Gupta, 2013). The adoption of the concept of codependency was primarily a grassroots effort that began with Al-Anon Family Groups in 1951, and continues today with groups like Co-Dependents Anonymous, founded in 1986 (see Cermak, 1991; Plant \& Plant, 2009).

Codependency, was once reserved to describe the experience of wives and close family members of alcoholics; however, it has become a broad-reaching term that describes a generic, dysfunctional style of relating to others (Stafford, 2001). In fact, Plant and Plant (2009) have argued that the concept of codependency in the United States, though popular, has become increasingly confused and complex. Notwithstanding the increasing complexity of the concept, codependency is still the go-to diagnosis for partners of addicts, including partners of individuals with sexual addiction - despite the growing body of evidence that the experience of these partners is qualitatively different from partners of individuals with substance addictions.

\section{The Experience of Partners of Sex Addicts}

Steffens and Rennie's The Traumatic Nature of Disclosure for Wives of Sexual Addicts (2006)-considered to be the seminal work in shifting the conceptualization of the experiences of partners of sex addicts-suggests that many, if not most, partners of sex addicts experience symptoms of trauma, rather than codependency (Minwalla, 2012; Minwalla, 2015; Schneider, 
Weiss, \& Samenow, 2012; Skinner, 2015). Minwalla (2011) suggested that partners of sex addicts experience symptoms similar to those with Post-Traumatic Stress Disorder (PTSD) or Rape Trauma Syndrome (RTS) (see also Minwalla, 2012; 2015). Symptoms described by partners often include: depression; self-protective behaviors; anger; obsessive thinking about the trauma; avoiding thinking about the trauma; intrusive thinking about the trauma; sleeplessness; nightmares; flashbacks; feelings of responsibility; fear; triggering and reactivity; anxiety; hypervigilance; and emotional arousal (Carnes, 2011; Minwalla, 2011; Schneider et al., 2012; Skinner, 2015; Zitzman \& Butler, 2009).

Defining trauma. According to DSM-5, traumatic events are ones where there is "exposure to actual or threatened death, serious injury, or sexual violence" (American Psychiatric Association, 2013, p. 271). Giordano et al. (2016) further explain that "individuals may directly experience or witness the trauma, hear of a loved one's traumatic event, or repeatedly hear of or see trauma (e.g., in one's occupation)" (p. 56). However, there are many who deem this definition of trauma to be too restrictive (Anders, Frazier, \& Frankfurt, 2011; Weathers \& Keane, 2007). Most notably, John Briere and Catharine Scott (2015) state that earlier editions of the DSM included threats to psychological integrity as traumatic events, however DSM-5 “does not consider events to be traumatic if they are merely highly upsetting but not life threatening... [therefore,] it undoubtedly underestimates the extent of actual trauma in the general population" (pp. 9-10). As such, Briere and Scott (2015) choose to define an event as traumatic if it is "extremely upsetting, at least temporarily overwhelms the individual's internal resources, and produces lasting psychological symptoms" (p. 10). Under this definition, the experiences of partners of sex addicts clearly qualify as trauma. 
Diagnosing trauma. According to the current edition of the DSM, there are five criteria that must be met in order for a diagnosis of PTSD to be given (American Psychiatric Association, 2013). The criteria include: (a) exposure to actual or threatened death, serious injury, or sexual violence; (b) intrusion symptoms associated with the trauma that began after the traumatic event; (c) persistent avoidance of stimuli associated with the traumatic event; (d) negative changes in mood and cognition; and (a) marked changes in arousal and reactivity. The complete DSM-5 criteria for PTSD are included in Figure 1. While most clinicians agree on Criteria B - E, Criterion A, which is generally considered the ultimate definition of trauma, has come under considerable fire over the years. (Anders et al., 2011; Weathers \& Keane, 2007). Recent studies suggest that, even when an event does not meet Criterion A, the event still has a traumatic effect (Anders et al., 2011; Giordano et al., 2016; Steffens \& Rennie, 2006; Weathers \& Keane, 2007). For example, Anders et al. (2011) completed a study in which events that both met and did not meet Criterion A were compared. Both types of events led to symptoms of PTSD; and events that did not meet Criterion A were actually associated with higher PTSD symptoms than Criterion A events (Anders et al., 2011). Steffens and Rennie (2006) found similar results in their study, reporting that $69 \%$ of participants met all of the criteria for PTSD except for Criterion A. In addition, $50 \%$ of the participants reported moderate to severe symptoms of PTSD (Steffens \& Rennie, 2006). The results of these studies and others suggest that Criterion A, which is considered to be the general definition of trauma, may need revision; and that PTSD can be experienced following a non-life-threatening event, such as the disclosure or discovery of a sexual addiction. 


\section{Treating Partners of Sex Addicts}

The current literature regarding the provision of mental health services for partners of sex addicts espouses two theoretical models for treating partners of sex addicts: the traditional Addiction (or Codependency) Model, which has been the model of choice for several decades; and the Trauma Model (Steffens \& Rennie, 2006).

The Addiction Model. In speaking of the Addiction Model, Minwalla (2012) stated, "The traditional sex addiction field to this day still [focuses]...on diagnosing partners as 'co-addicts' and emphasizing treatment of codependency" (para. 9). In the context of sexual addiction, Steffens and Rennie (2006) suggested that the Addiction Model "centers upon the [partner's] addictive or obsessive relationship with an addict and predisposition to the development of co-addiction due to the [partner's] traumatic and dysfunctional pasts" (p. 261). This model also conceptualizes the partner as having his or her own disease that contributes to the continuation of the sexual addiction (Steffens \& Rennie, 2006).

Recent research has raised some specific concerns about the Addiction Model, specifically in the context of sexual addiction. First, while some professionals who ascribe to the Addiction Model do recognize the shock the partner experiences related to the disclosure of the sex addiction, and will even identify symptoms of PTSD, they generally do not actively treat the partner for PTSD (Corley \& Schneider, 2002). Rather, they endorse the codependency aspect of the Addiction Model with an individual whose "accurate perceptions and feelings [of trauma] are consistently and often vigorously denied," and such endorsement can actually foster the symptoms of codependency (Schneider et al., 2012, pp. 135-136).

Next, partners can become confused about whether they are codependent or victims of trauma (Schneider et al., 2012). In a recent study of partners of sex addicts, Corley, Schneider, 
and Hook (2012) reported that $41.3 \%$ of respondents agreed that the term co-addict or codependent described them, and $76.9 \%$ concurred that interpersonal relationship trauma described their experience. To better exemplify the confusion, the authors looked at participants' responses to both questions together. The authors of the study also found that, " $30.8 \%$ of partners said both terms described them, $29.7 \%$ labeled themselves as victims but not co-addicts, and $16.5 \%$ labeled themselves as victims and somewhat as co-addicts (other combinations had a small frequency of responses)"(Corley et al., 2012, p. 272).

Finally, it has been asserted that some individuals may become "disoriented and retraumatized by traditional co-addiction treatment interventions that focus on educating and helping partners with their 'own disease' called co-addiction while ignoring the treatment of trauma (Minwalla, 2012, para. 11-12). Minwalla (2012) also suggests that this retraumatization could be considered a form of gender-based violence. As such, he warns that professionals should take extreme care in employing the Addiction Model when an individual manifests symptom of trauma.

The Trauma Model. Several recent studies suggest that partners of sex addicts actually experience trauma, rather than codependency. This is especially true with regards to the discovery or disclosures of sexually compulsive and addictive behavior. There is currently a lack of empirical evidence to support these findings, although several researchers have begun to make progress towards endorsing the validity of the trauma model (Carnes \& O'Connor, 2016; Steffens, 2005; Steffens \& Rennie, 2006).

Steffens and Rennie (2006) explain that the trauma model, "rather than conceptualizing [the partner's] symptomatic responses as arising from her own dysfunction and addiction, [the partner's] responses serve as a reaction to a stressor that is traumatic in nature, in predictable 
emotional, behavioral, and physiological ways" (p. 261). Another author described the trauma model emphasizing "the betrayal, the shock, the PTSD symptoms, and the ultimate victimization of the partner, when the sexual addict's behaviors are discovered or finally acknowledged, with special underscoring that that partner committed no wrong in being victimized this way" (Hentsch-Cowles \& Brock, 2013, p. 328). In the context of sexual addiction, discovery is defined as finding out about a sexual addiction, and disclosure is being told about a sexual addiction by the one experiencing the addiction (Carnes \& O'Connor, 2016; Minwalla, n.d.).

According to Carnes (2011), discovery of a partner's sex addiction is “a trauma that, for many partners, causes an acute stress reaction and possibly symptoms of post-traumatic stress disorder (PTSD)" (p. 3; see also Baird, 2011). Carnes also reported that, "Partners of sex addicts do experience significant trauma-related consequences as a result of the discovery or disclosure of the addiction" (Carnes \& O'Connor, 2016, p. 149; see also Steffens \& Rennie, 2006). Therefore, utilizing a Trauma Model of treatment would appear to be the more appropriate course of action for assisting these individuals than is the Addiction Model.

Trauma model assessments. In an effort to better understand the experience of partners of sex addicts, Carnes and O'Connor (2016) recently published a confirmatory analysis of the Partner Sexuality Survey (PSS). The PSS is designed to measure the impact of sexual addiction on the emotional well-being and sexuality of the partner of the sex addict. The items on this assessment were created based on a qualitative study of the experiences of partners of sex addicts (Carnes \& O'Connor, 2016; see also Minwalla, 2011). However, while the PSS contributes to the reconceptualization of the experience of partners of sex addicts, it does not assess the trauma experienced by partners of sex addicts. Thus, there is a need for an instrument that can assess the traumatic nature of discovery and/or disclosure. 


\section{Purpose of the Study}

In an effort to expand the body of knowledge as it pertains to the trauma model, this study examined the responses of partners of individuals with sexually compulsive behaviors to The Trauma Inventory for Partners of Sex Addicts (TIPSA), both version 2.0 and 2.1 (Skinner, 2015, Aug 13). The TIPSA is designed to help mental health professionals assess the trauma experienced by partners of sex addicts. The items for this instrument were written to reflect diagnostic criteria for PTSD as published in the DSM-IV-TR (American Psychiatric Association, 2000), which was the most current version of the DSM when the TIPSA was created.

Additionally, the factor structure of the TIPSA was hypothesized to reflect the five categorical criteria for PTSD as constituted in DSM-5 (American Psychiatric Association, 2013). Criterion A addresses exposure to Threat; Criterion B, the reliving the traumatic event; Criterion C, avoidant behaviors; Criterion D, negative cognitions; and Criterion E, emotional arousal.

Accordingly, the purpose of this study was to identify and examine the underlying latent factor structure of the TIPSA; and, to determine whether that factor structure aligned with the factor structure for PTSD as currently constituted in DSM-5.

\section{Research Questions}

There were two primary research questions in this study. The first question was: To what extent does the hypothesized factor structure of the TIPSA align with the DSM-5 criteria for PTSD? This question aimed to establish construct validity for the TIPSA, and allow mental health professionals to better identify symptoms of PTSD in partners of sex addicts.

The second question was: How can the TIPSA be refined so that it will maintain its construct validity and reliability while becoming more parsimonious and easier to administer? 
This question also helped improve the validity of the TIPSA. The overall hypothesis was that the TIPSA would show solid construct validity, and that parsimony would be achievable.

\section{CHAPTER 2}

\section{Review of Literature}

\section{Defining Addiction}

Around 1900, a medical definition of addiction emerged which suggested a disease model characterized by a "strong devotion to or inclination to usage of some drug" (Vohs \& Baumeister, 2009, p. 233). Since that time, the terms addiction and dependence have been associated with the heavy use of "psychoactive drugs such as alcohol, tobacco, (and) prescribed and illicit psychoactive drugs" (Plant \& Plant, 2009, p. 260). Engagement in these types of behaviors usually begins to interfere with an individual's ability to function in other domains of life (Grant, Potenza, Weinstein, \& Gorelick, 2010). Over time, addiction has come to connote a diminished control over one's behavior despite knowledge of the adverse consequences (Grant et al., 2010).

But addiction is not merely an individual disease. More than 60 years ago, Alcoholics Anonymous recognized that addiction affected more than just the individual with the addiction, stating that over time, the personalities and behaviors of family members can become distorted, and eventually the entire family is considered ill (Alcoholics Anonymous, 2001). Today, addiction is still considered to be a familial disease, affecting all intimate relationships of the addicted individual (Cermak, 1991; Marks, Blore, Hine, \& Dear, 2012; Panaghi, Ahmadabadi, Khosravi, Sadeghi, \& Madanipour, 2016; Prest \& Protinsky, 1993). This familial disease is currently known as codependency. 


\section{Codependency}

The concept of codependency emerged in the 1960's and 1970's as a means of describing wives of alcoholics (Cermak, 1991; Harkness, Swenson, Madsen-Hampton, \& Hale, 2001). Originally, the term was co-alcoholic and it referred to a pattern of enabling, or "aiding and abetting an addicted person's behavior through over-zealous helping" (Harkness et al., 2001, p. 160). As alcoholism was later incorporated into the more general categories of chemical dependence and addictive disease, co-alcoholism changed into co-addiction and, eventually, codependence (Cermak, 1991).

Because of its roots in the field of chemical dependency, many mental health professionals were at first hesitant to embrace the concept of codependency (Morgan, 1991). However, the proliferation of Twelve-Step programs has increased the reach of the terms addiction and dependence (Plant \& Plant, 2009). Now, more than seventy years after its initial introduction, codependency has become the go-to diagnosis or conceptualization for spouses, partners, and family members of individuals with addictions (Ferree, 2002; Hentsch-Cowles \& Brock, 2013; King, 2003; Marks et al., 2012; Matheny, 1998; Milrad, 1999; Minwalla, 2012; Tripodi, 2006).

Defining codependency. Over the years, various theoretical frameworks have sought to define codependency. Subby (1984) defined codependency from a family systems and ego psychology approach. He stated, “(Codependency is) an emotional, psychological, and behavioral condition that develops as a result of an individual's prolonged exposure to, and practice of, a set of oppressive rules - rules which prevent the open expression of feeling as well as the direct discussion of personal and interpersonal problems" (Subby, 1984, p. 26). 
Beattie (1987) defined codependency using interpersonal terms. She stated, "[A] codependent person is one who has let another person's behavior affect him or her, and who is obsessed with controlling that person's behavior" (Beattie, 1987, p. 19). Morgan (1991) clarifies this thought, saying, “'codependency is primarily a reactionary process'...(whereby) individuals react to the 'problems, pains, and behaviors' of themselves and others instead of acting in ways that are adaptive" (p. 723).

Whitfield (1989) uses a definition similar to Beattie's. He defines codependency as, "any suffering and/or dysfunction that is associated with or results from focusing on the needs and behaviors of others" (Whitfield, 1989, p. 19). Along the same lines, Larsen (1987) emphasized both interpersonal and behavioral aspects of codependency in his definition. He stated, "(Codependency is) those self-defeating, learned behaviors that diminish our capacity to initiate or participate in loving relationships" (Larsen, 1987, p. 14).

Wegscheider-Cruse (1985) provided what Morgan (1991) deems "one of the more operational definitions of codependency" (p. 724). Her definition of codependency is:

a specific condition that is characterized by preoccupation and extreme dependency (emotionally, socially, and sometimes physically) on a person or object. Eventually, this dependence on another person becomes a pathological condition that affects the codependent in all relationships. (Wegscheider-Cruse, 1985, p. 2)

Conceptualizing codependency. Beyond the frameworks described above, the term codependency can be viewed in at least three different levels of conceptualization (Cermak, 1991; Morgan, 1991). First, it can be used a didactic tool to help normalize and legitimize the feelings that family members experience (Cermak, 1991; Morgan, 1991). Focusing on codependence can "facilitate a shift within the family from a blaming mode...to a personal 
responsibility mode in which family members...become more accepting of their own humanness" (Morgan, 1991, p. 722). Essentially, the educational purpose of the term codependency is to help family members refocus their attention and control to their own behaviors, rather than the behavior of others.

Second, codependence can also be conceptualized as a psychological construct that complexly bridges the sociology of the rules that govern the family system and the roles that are created by the system (Cermak, 1991). The psychological concept of this term tends to be used primarily by clinicians in their communications with each other. It is a way of abstracting "the psychological processes associated with codependent functioning” (Morgan, 1991, p. 722)

The third level of meaning is the one with which the general population is most familiar. In this definition, codependence can be seen as a disease in and of itself. One can either experience the consequences of codependency, or be actively codependent. Some believe calling codependency a disease is ridiculous "because it is a culturally conditioned response of an overfunctioning person in relationship with an underfunctioning person" (Mecham, 1990-1991, as cited in Anderson, 1994, p. 678). Much has been said about the universal nature of codependent traits, and many clinicians do not want to endorse a means of labelling and exploiting "characteristics that exist, to varying degrees, in most people" (Morgan, 1991, p. 724). Morgan (1991), however, argues that "Just as narcissism exists as a nearly universal human trait, narcissistic personality disorder applies only to those individuals who manifest objective dysfunction. This same logic certainly could apply to codependency as well” (p. 724).

In the face of this hesitation, Cermak (1991) developed a framework for including codependency as a personality disorder in diagnostic manuals (see also Morgan, 1991). He stated that among personality disorders, codependence most closely resembles narcissism, with the 
same core dynamics operating within each disorder, although often in opposite directions. "Because both co-dependents and narcissists focus on the same person (the narcissistic member of the relationship), their interaction is symmetric and synergistic" (Cermak, 1991, p. 270).

In addition, relationships for both narcissists and codependents are built on mirroring. For the narcissist, if mirroring stops then the relationship ends. "The narcissist cannot relate to an autonomous individual - (so) that person ceases to exist. (However), [for] co-dependents, if the relationship ends, their own existence is threatened...If they are not mirrors, they are nothing" (Cermak, 1991, p. 271).

According to Cermak (1991) there are two types of codependency. Primary codependence is crystalized in childhood and becomes core to a child's baseline character. Secondary codependence involves a gradual onset of traits during adulthood, and is usually in response to a family member's chemical dependence or other addictive behavior. As such, secondary codependents have a level of normal to which they can return but primary codependents do not (Cermak, 1991).

Diagnosing codependency. The disease model of codependency lends itself to the development of diagnostic criteria (Cermak, 1991). However, there has been reluctance to establish clinical criteria for diagnosing codependency (Anderson, 1994; Morgan, 1991). Cermak (1991) and Morgan (1991) suggested that those who are overly-cautious about such matters should review the difference between traits and disorders. With reference to the distinction between the two, Cermak (1986) stated that, "a consistent pattern of traits and behaviors can create significant dysfunction" (as cited in Morgan, 1991, p. 722) and that a diagnosis of codependency should only be made "in the face of identifiable dysfunction resulting from excessive rigidity or intensity associated with these traits (as cited in Morgan, 1991, p. 724). 
In this context, codependency “is used to describe a 'disease entity,' just as panic disorder, borderline personality disorder, and post-traumatic stress disorder are diagnostic entities" (Morgan, 1991, p. 722). Some of the diagnostic traits and behaviors of codependency may include: ignorance; compulsion; denial; self-sacrifice; shame; frozen feelings or emotional suppression; low self-esteem; and stress-related medical conditions (Cermak, 1991; Marks et al., 2012; Morgan, 1991).

Assessing and treating codependency. In her 2001 article, Stafford identified eight separate instruments that attempt to measure codependency as a personality variable. According to her research, the eight measures are: Friel Adult Child/Co-dependency Assessment Inventory; The Codependency Assessment Questionnaire (CAQ); The Co-Dependency Inventory (CDI); The Spann-Fischer Codependency Scale (SFCDS); The Beck Codependency Assessment Scale (BCAS); The Eight-Factor Codependency Scale (EFCDS); Codependent Questionnaire (CdQ); and The Codependency Assessment Tool (CODAT) (Stafford, 2001). In addition to those listed in Stafford's article, two other assessments exist. Harkness et al. (2001) created the Idaho Codependency Scale. And Marks, Blore, Hine, and Dear (2012) created the Composite Codependency Scale (CCS) to measure underlying facets of codependency identified by a thematic analysis of the most published definitions of codependency (Dear, Roberts, \& Lang, 2004; in Marks et al., 2012).

Treatment for codependence has traditionally been Twelve-Step programs (such as AlAnon, CoSa, etc.) along with psychoeducation (Harkness et al., 2001; Tripodi, 2006). These programs tend to adhere to the disease model of addiction and co-addiction, which has caused some concern among those who do not view codependency as a disease (Plant \& Plant, 2009). 
Psychotherapy, in addition to other treatment methods, is also suggested, and is often required for individuals with primary codependence (Cermak, 1991).

Controversy of codependency. Recent research has called into question the applicability of the term codependence, with many wondering if the concept has become an outdated, and inaccurate, means of making sense of the relationship between partners and addicts (Panaghi et al., 2016). Some researchers suggest that the concept of codependency has extended beyond the realm of addiction treatment and has become a way to describe the dysfunctional dynamics of any relationship, not just those between partners and addicts (Harkness et al., 2001; Lindley \& Giordano, 1999; Springer, Britt, \& Schlenker, 1998; Wells, Hill, Brack, Brack, \& Firestone, 2006). Shaef declared codependency to be an epidemic, resulting from a codependent society (as cited in Prest \& Protinsky, 1993), and Lindley and Giordano (1999) have gone so far as to assert that the term codependency has become so broad that is has begun to "lose [it's] theoretical rigor and explanatory power. If codependency explains everything, then it really explains nothing" (p. 60). These arguments are gaining traction in the addiction community at large, and are becoming especially prevalent among researchers who are branching out of the field of traditional chemical dependency and addiction into the field of compulsive behaviors and addiction.

\section{Behavioral Addiction}

Some researchers maintain that addiction must involve "the self-administration of an agent to alter the experience of self or the environment" (Martin \& Petry, 2005, p. 1). However, others argue that "we must also include the repetitive and harmful nature of many other behaviors in the human repertoire" (Martin \& Petry, 2005, p. 1). A number of recent publications suggest that behaviors such as gambling, eating, sex, and spending money may be just as addictive as substances (Grant et al., 2010; Morgan, 1991; Plant \& Plant, 2009), and that these 
behaviors can produce short-term rewards that may engender addictive behavior (Grant et al., 2010).

Urges, cravings, or built-up tension usually precede actions in both types of addictions. Emotional dysregulation may contribute to these urges and feelings (Grant et al., 2010; Martin \& Petry, 2005). Decreased anxiety and an emotionally positive mood state are common results of addictive behaviors. Over time, both those facing behavioral addictions and those facing substance addictions report a need to increase the intensity or duration of the behavior in order to achieve the same results. Just as with substance addiction, behavioral addictions may become more of a compulsion or habit. Reinforcement, therefore, may change from a positive release of anxiety to a negative warding off withdrawal symptoms (Grant et al., 2010; Martin \& Petry, 2005). Furthermore, financial and marital problems are also common in both types of dependencies, with addicted individuals committing "illegal acts such as theft, embezzlement, and writing bad checks, to either fund their addictive behavior or cope with the consequences of the behavior" (Grant et al., 2010, p. 234).

Notwithstanding the similarities between chemical and behavioral addictions, there is still a lack of research and empirical evidence to support classifying behavioral addictions as independent disorders beyond the current group-classification as impulse control disorders (Grant et al., 2010). The one exception is gambling, which was recently re-classified as part of the "Substance-related and Addictive Disorders" in The Diagnostic and Statistical Manual of Mental Disorders (5th ed.; DSM-5; American Psychiatric Association, 2013).

Sexual addiction. Individuals who struggle with sexually compulsive behaviors often experience symptoms of cravings, tolerance, and withdrawal, as do those with substance addictions (Carnes, 2011; Kraus, Voon, \& Potenza, 2016). Sexual addiction was considered for 
inclusion in DSM-5; however, despite the common symptomatology, many researchers still do not consider sexually compulsive behaviors to be addictions (Kraus et al., 2016). These professionals tend to use the term hypersexual disorder rather than sexual addiction (Carnes, 2011; Kafka, 2010). Still others prefer to refer to these behaviors as a sexual disorder, a mood disorder, or an impulse disorder (Kraus et al., 2016). Perhaps in an effort to appease both camps, sexual addiction/compulsivity is the most frequently used term in the current literature (Steffens, 2005).

Codependency and sexual addiction. Codependency has become the go-to diagnosis or conceptualization for partners of individuals with addictions, with sexually compulsive behaviors or addictions (Ferree, 2002; Hentsch-Cowles \& Brock, 2013; King, 2003; Marks et al., 2012; Matheny, 1998; Milrad, 1999; Minwalla, 2012; Tripodi, 2006). However, mounting research indicates that codependency may not be an accurate description of the experiences of these partners. It has been suggested that "Existing models for treating partners of sex addicts that are based solely on co-addiction and codependency are inadequate, clinically contra-indicated and wrought with ethical and moral challenges" (Minwalla, 2012, para. 11). This contraindication of codependency dovetails with the reluctance of the professional community to accept sexual addiction as a clinical condition (Kraus et al., 2016).

\section{CHAPTER 3}

\section{Method}

This study was conducted using an existing data set provided by Dr. Kevin B. Skinner, a Utah-based Licensed Marriage and Family Therapist (LMFT) who specializes in providing therapy services for partners of sex addicts, and is the primary author of the instrument being examined. The data were a combination of responses to two different versions of the Trauma 
Inventory for Partners of Sex Addicts (TIPSA). Both versions of the TIPSA are described in subsequent sections of this paper.

The data for this study were initially provided in two separate SPSS files, generated from Survey Monkey - the administration platform for the survey. Upon receipt of the data set, all identifying information (such as IP address and email) was scrubbed, and the data sets were combined into a single SPSS file. Approval to use the data was obtained from the Brigham Young University Institutional Review Board in January 2017.

\section{Participants}

Participant recruitment. The data for this study was consisted of responses from 3,199 respondents to the Trauma Inventory for Partners of Sex Addicts (TIPSA) version 2.0 and 2.1. A majority of the participants were recruited through a blogpost, titled The Lasting Effects of Sexual Betrayal, written for PsychologyToday.com (Skinner, 2015). The post, which discussed the traumatic nature of discovery and disclosure of sex addictions, received over 3,000 social media "likes" and included an in-text hyperlink to an online-version of the TIPSA. Additional respondents were also recruited through Dr. Skinner's private practice and his website, BloomForWomen.com. All respondents voluntarily navigated to an online-version of the TIPSA where they were informed that their responses would be used for research purposes. Consent to participate was inferred by participants' completion of the TIPSA. It should be noted that there was selection bias within the sample due to the self-selection of participants into the study; however, this selection bias was not a concern for the current study.

Participant demographics. Demographic information for the 3,199 respondents was collected during administration; however, this information was gathered at the end of the TIPSA, rather than at the beginning. As such, roughly $22 \%$ of the sample did not provide demographic 
information. Of the approximately $78 \%$ of respondents who did provide the requested information, $90.5 \%$ were between the ages of 21 to $55,58.2 \%$ were currently married, $85.6 \%$ had at least some college education, and $93.4 \%$ identified as female.

Information regarding religious preference was also collected. There was a slight discrepancy between the two versions of the TIPSA for the item "What is your religious preference?" Four additional options were added to TIPSA 2.1, which were: Agnostic; Lutheran; Muslim; and Wicca. This discrepancy necessitated the recoding of responses to this item from TIPSA 2.0 to match the coding from TIPSA 2.1 in order to maintain consistency of the coding structure. In addition to the necessary recoding, respondents were given the option of providing their religious preference in a text box labeled "other."

All text responses were examined to determine if the written response might fit within one of the pre-defined categories. When a response did fit an existing category, the respondent's answer to the religious preference item was updated. Through this process an additional category labeled "Spiritual" was identified and created. Respondents who indicated "Spiritual" in their written responses also had their answer to the religious preference item updated. Finally, written responses that did not fall within any existing category were coded as "Other" so as to streamline the demographic process. Following the restructuring of the religious preference item, $61.2 \%$ of respondents were identified as Christian (Pew Research Center, 2015). Participants were not asked about ethnicity or race. A comprehensive view of participant demographic information is included in Table 1. 
Table 1

Demographics of Respondents $(N=3,199)$

\begin{tabular}{|c|c|c|c|c|c|}
\hline Category & $\mathrm{n}$ & $\%$ & Category & $\mathrm{n}$ & $\%$ \\
\hline Gender & & & Relationship Status & & \\
\hline Male & 164 & 5.13 & Single & 224 & 7.00 \\
\hline Female & 2,339 & 73.12 & Committed Relationship & 613 & 19.16 \\
\hline Unreported & 696 & 21.76 & Married & 1,192 & 37.26 \\
\hline Age & & & Married, but Separated & 265 & 8.28 \\
\hline $18-20$ & 49 & 1.53 & Divorced & 210 & 6.56 \\
\hline $21-25$ & 234 & 7.31 & Unreported & 695 & 21.73 \\
\hline $26-30$ & 352 & 11.00 & Education & & \\
\hline $31-35$ & 421 & 13.16 & GED & 79 & 2.47 \\
\hline $36-40$ & 389 & 12.16 & High School Graduate & 281 & 8.78 \\
\hline $41-45$ & 392 & 12.25 & Some College & 738 & 23.07 \\
\hline $46-50$ & 256 & 8.00 & Associate Degree & 284 & 8.88 \\
\hline $51-55$ & 226 & 7.06 & Bachelor Degree & 681 & 21.29 \\
\hline $56-60$ & 120 & 3.75 & Graduate Degree & 442 & 13.82 \\
\hline Over 60 & 68 & 2.13 & Unreported & 694 & 21.69 \\
\hline Unreported & 692 & 21.63 & Religious Preference & & \\
\hline Previous Mental Health Diagnosis & & & Agnostic & 128 & 4.00 \\
\hline Anxiety only & 156 & 4.88 & Atheist & 170 & 5.31 \\
\hline ADHD only & 50 & 1.56 & Born Again Christian & 165 & 5.16 \\
\hline Bipolar Disorder only & 6 & 0.19 & Baptist & 67 & 2.09 \\
\hline Borderline Personality only & 5 & 0.16 & Buddhist & 38 & 1.19 \\
\hline Depression only & 269 & 8.41 & Catholic & 290 & 9.07 \\
\hline Narcissism only & 2 & 0.06 & Christian & 545 & 17.04 \\
\hline PTSD only & 52 & 1.63 & Hindu & 18 & 18 \\
\hline Substance Related only & 6 & 0.19 & Jewish & 22 & 0.69 \\
\hline Depression + Anxiety & 399 & 12.47 & Lutheran & 27 & 0.84 \\
\hline PTSD + Dep and/or Anxiety & 251 & 7.85 & Latter-day Saint (Mormon) & 308 & 9.63 \\
\hline PTSD + Any Other Combo & 115 & 3.59 & Methodist & 32 & 1.00 \\
\hline Any Other Combination & 201 & 6.28 & Muslim & 33 & 1.03 \\
\hline None of the Above & 896 & 28.01 & Protestant & 48 & 1.50 \\
\hline \multirow[t]{5}{*}{ Unknown } & 791 & 24.73 & Wicca & 18 & 0.56 \\
\hline & & & I am not Religious & 518 & 16.19 \\
\hline & & & Spiritual & 31 & 0.97 \\
\hline & & & Other & 35 & 1.09 \\
\hline & & & Unknown & 706 & 22.07 \\
\hline
\end{tabular}


In addition to demographic information, participants were asked if they had ever been diagnosed with a mental health disorder. Participants were given eight diagnoses to select from, and were allowed multiple selections, including "None of the Above." Of those who answered the question, approximately $28 \%$ indicated no previous diagnosis, and just over $13 \%$ indicated a prior diagnosis of PTSD (either alone or in combination with another diagnosis). Additional information regarding participant mental health history is also included in Table 1. Frequencies and descriptive statistics were calculated using IBM SPSS Statistics for Windows, Version 24.

Participant inclusion. Only $6 \%$ of participants identified themselves as male. Thus, only participants who identified as female were included in the sample. This subset was initially created by utilizing the "Select Cases" function in SPSS 24; only those cases coded as "female" were selected. This file was exported as a .csv file, and was used for randomization as well as for data analysis.

Randomization. After selecting only the female cases, the subset was randomly split into three subgroups: one to be used for the confirmatory factor analysis (CFA) of the original model and subsequent respecification; and two to be used for cross validation (CV1 and CV2). The subgroups were randomly created using Microsoft Excel. Demographics for the resulting subgroups are provided in Table 2.

Missing data. The percent missingness for the 53 TIPSA items from the female-only subset ranged from $0.04 \%$ to $0.38 \%$, and the listwise deletion percentage was $7.05 \%$. The range of individual missingness among participants was $1.89 \%$ (one item) to $35.85 \%$ (19 items). Only one respondent left 19 items unanswered; three left 10 to 12 items unanswered; 32 left two to five items unanswered; and 129 left one item unanswered. Thus, only 165 respondents (or $7.05 \%$ ) contributed to missingness of data. 
Table 2

Demographics of Female-only Subgroups $(N=2,339)$

\begin{tabular}{|c|c|c|c|c|c|c|}
\hline \multirow[b]{2}{*}{ Category } & \multicolumn{2}{|c|}{ CFA } & \multicolumn{2}{|c|}{ CV1 } & \multicolumn{2}{|c|}{ CV2 } \\
\hline & $(n=779)$ & $\%$ & $(n=780)$ & $\%$ & $(n=779)$ & $\%$ \\
\hline \multicolumn{7}{|l|}{ Age } \\
\hline $18-20$ & 14 & 1.80 & 22 & 2.82 & 9 & 1.15 \\
\hline $21-25$ & 55 & 7.06 & 73 & 9.36 & 83 & 10.64 \\
\hline $26-30$ & 106 & 13.61 & 116 & 14.87 & 116 & 14.87 \\
\hline $31-35$ & 132 & 16.94 & 134 & 17.18 & 125 & 16.03 \\
\hline $36-40$ & 119 & 15.28 & 113 & 14.49 & 125 & 16.03 \\
\hline $41-45$ & 137 & 17.59 & 112 & 14.36 & 117 & 15.00 \\
\hline $46-50$ & 82 & 10.53 & 81 & 10.38 & 77 & 9.87 \\
\hline $51-55$ & 78 & 10.01 & 70 & 8.97 & 67 & 8.59 \\
\hline $56-60$ & 34 & 4.36 & 34 & 4.36 & 43 & 5.51 \\
\hline Over 60 & 21 & 2.70 & 24 & 3.08 & 16 & 2.05 \\
\hline Unreported & 1 & 0.13 & 1 & 0.13 & 2 & 0.26 \\
\hline \multicolumn{7}{|l|}{ Relationship Status } \\
\hline Single & 57 & 7.32 & 71 & 9.10 & 63 & 8.08 \\
\hline Committed Relationship & 184 & 23.62 & 201 & 25.77 & 187 & 23.97 \\
\hline Married & 377 & 48.40 & 351 & 45.00 & 402 & 51.54 \\
\hline Married, but Separated & 90 & 11.55 & 85 & 10.90 & 75 & 9.62 \\
\hline Divorced & 68 & 8.73 & 69 & 8.85 & 53 & 6.79 \\
\hline Unreported & 3 & 0.39 & 3 & 0.38 & 0 & 0.00 \\
\hline \multicolumn{7}{|l|}{ Education } \\
\hline GED & 27 & 3.47 & 23 & 2.95 & 22 & 2.82 \\
\hline High School Graduate & 88 & 11.30 & 84 & 10.77 & 85 & 10.90 \\
\hline Some College & 214 & 27.47 & 227 & 29.10 & 254 & 32.56 \\
\hline Associate Degree & 91 & 11.68 & 99 & 12.69 & 80 & 10.26 \\
\hline Bachelor Degree & 228 & 29.27 & 201 & 25.77 & 209 & 26.79 \\
\hline Graduate Degree & 131 & 16.82 & 144 & 18.46 & 127 & 16.28 \\
\hline Unreported & 0 & 0.00 & 2 & 0.26 & 3 & 0.38 \\
\hline
\end{tabular}


Table 2 continued

\begin{tabular}{|c|c|c|c|c|c|c|}
\hline \multirow[b]{2}{*}{ Category } & \multicolumn{2}{|c|}{ CFA } & \multicolumn{2}{|c|}{ CV1 } & \multicolumn{2}{|c|}{ CV2 } \\
\hline & $(n=779)$ & $\%$ & $(n=780)$ & $\%$ & $(n=779)$ & $\%$ \\
\hline \multicolumn{7}{|l|}{ Religious Preference } \\
\hline Agnostic & 39 & 5.01 & 36 & 4.62 & 37 & 4.74 \\
\hline Atheist & 53 & 6.80 & 50 & 6.41 & 46 & 5.90 \\
\hline Born Again Christian & 54 & 6.93 & 51 & 6.54 & 53 & 6.79 \\
\hline Baptist & 20 & 2.57 & 21 & 2.69 & 23 & 2.95 \\
\hline Buddhist & 14 & 1.80 & 10 & 1.28 & 11 & 1.41 \\
\hline Catholic & 105 & 13.48 & 86 & 11.03 & 77 & 9.87 \\
\hline Christian & 174 & 22.34 & 176 & 22.56 & 164 & 21.03 \\
\hline Hindu & 4 & 0.51 & 4 & 0.51 & 7 & 0.90 \\
\hline Jewish & 7 & 0.90 & 6 & 0.77 & 7 & 0.90 \\
\hline Lutheran & 10 & 1.28 & 11 & 1.41 & 5 & 0.64 \\
\hline Latter-Day Saint (Mormon) & 95 & 12.20 & 89 & 11.41 & 117 & 15.00 \\
\hline Methodist & 6 & 0.77 & 11 & 1.41 & 14 & 1.79 \\
\hline Muslim & 9 & 1.16 & 13 & 1.67 & 7 & 0.90 \\
\hline Protestant & 12 & 1.54 & 19 & 2.44 & 14 & 1.79 \\
\hline Wicca & 6 & 0.77 & 5 & 0.64 & 5 & 0.64 \\
\hline I am not religious & 144 & 18.49 & 163 & 20.90 & 171 & 21.92 \\
\hline Spiritual & 12 & 1.54 & 12 & 1.54 & 6 & 0.77 \\
\hline Other & 12 & 1.54 & 10 & 1.28 & 9 & 1.15 \\
\hline Unreported & 3 & 0.39 & 7 & 0.90 & 7 & 0.90 \\
\hline \multicolumn{7}{|l|}{ Previous Mental Health Diagnosis } \\
\hline Anxiety only & 52 & 6.68 & 46 & 5.90 & 48 & 6.15 \\
\hline ADHD only & 16 & 2.05 & 12 & 1.54 & 12 & 1.54 \\
\hline Bipolar Disorder only & 0 & 0.00 & 2 & 0.26 & 1 & 0.13 \\
\hline Borderline Personality only & 1 & 0.13 & 3 & 0.38 & 1 & 0.13 \\
\hline Depression only & 90 & 11.55 & 86 & 11.03 & 78 & 10.00 \\
\hline Narcissism only & 0 & 0.00 & 0 & 0.00 & 1 & 0.13 \\
\hline PTSD only & 13 & 1.67 & 24 & 3.08 & 12 & 1.54 \\
\hline Substance Related only & 1 & 0.13 & 2 & 0.26 & 2 & 0.26 \\
\hline Depression + Anxiety & 115 & 14.76 & 132 & 16.92 & 129 & 16.54 \\
\hline PTSD + Dep and/or Anxiety & 81 & 10.40 & 80 & 10.26 & 76 & 9.74 \\
\hline PTSD + Any Other Comb & 35 & 4.49 & 41 & 5.26 & 36 & 4.62 \\
\hline Any Other Combination & 47 & 6.03 & 68 & 8.72 & 76 & 9.74 \\
\hline None of the Above & 300 & 38.51 & 255 & 32.69 & 274 & 35.13 \\
\hline Unreported & 28 & 3.59 & 29 & 3.72 & 34 & 4.36 \\
\hline
\end{tabular}


To test for type of missingness, a new dichotomous variable was created. Participants with no missing data on any the 53 TIPSA items were assigned a value of 0 for this variable, and those with at least one missing response were assigned a value of 1 . Correlation of the dummy variable to demographic variables and the 53 TIPSA items revealed significant correlation with only10 variables.

Five of the correlations between the dummy variable and the TIPSA items were significant at the .05 level. The items significantly correlated with the dummy variable at this level were: Item 2 (-0.041); Item 9 (-0.047); Item 22 (-0.041); Item 49 (0.046); and Relationship Status (-0.045). Five items were also significant at the .01 level. The items correlated with the dummy variable at this level were: Item 10 (-0.058); Item 28 (-0.055); Item 29 (-0.063); Item 47 (-0.061); and Age Range (-0.060). The significant correlations between items and the dummy variable indicate a missing at random (MAR) relationship.

\section{Measures}

The Trauma Inventory for Partners of Sex Addicts (TIPSA) was originally created by Skinner, Knowlton, and Manning (K. Skinner, personal communication, October 12, 2017). In talking with each other, they realized that many of their clients, who were partners of sex addicts, showed symptoms of Post-Traumatic Stress Disorder (PTSD) rather than codependency. Following this realization, Skinner recalled, "[W]e wanted to know whether trauma was present just in clients we were seeing or if it was present in the general population of individuals whose [partners] were sexually acting out" (Skinner, 2015, para. 10). The TIPSA was the result of this collaboration.

After its original creation, Skinner modified the TIPSA to match the five diagnostic categories of PTSD as outlined in the Diagnostic and Statistical Manual of Mental Disorders 
(DSM-IV-TR) (American Psychiatric Association, 2000). The result was "one of the first assessments, if not the very first, that looked at trauma that stemmed from a spouse's sexual behaviors" (Skinner, 2015, para. 10).

The Trauma Inventory for Partners of Sex Addicts (TIPSA) 2.0. TIPSA 2.0 is Skinner's updated version of the original TIPSA and is an online instrument consisting of 64 items. The first 53 items are endorsed on a 5-point Likert scale from 1 (never) to 5 (always), with intermediate categories of 2 (occasionally/rarely), 3 (about half the time), and 4 (more often than $n o t$ ). The items assess the frequency of symptoms commensurate with the Post-Traumatic Stress Disorder (PTSD) criteria published in the DSM-IV-TR (American Psychiatric Association, 2000). Items 54 through 56 are intended to assess the direct impact of the partner's addiction on the respondent's life. Item 57 asks for information about the sexual behaviors in which the respondent's partner has been involved. Items 58 through 62 request demographic information from the respondent; and item 63 asks for a self-reported mental health history from there respondent. The final item allows the respondent to request additional support by submitting his or her email address. The entire instrument utilized seven webpages, and allows respondents to navigate between the pages until the survey is submitted. There are no current psychometric properties for TIPSA 2.0.

The Trauma Inventory for Partners of Sex Addicts (TIPSA) 2.1. TIPSA 2.1 is identical to TIPSA 2.0 with the exception of the item regarding religious preference (as discussed above) and eight additional items which were designed to gather information regarding the denial ("gaslighting") behaviors of the sex addict. These items were inserted prior to the demographic items and necessitated the inclusion of an additional webpage. Thus, version 2.1 is an eight-page instrument with 72 items, and no current psychometric properties. For the purposes 
of this study, the additional eight items from TIPSA 2.1 were excluded from the analyses. Accordingly, only the common 53 items from both TIPSA 2.0 and 2.1 were included in Appendix A. Of the female-only subset which was utilized for data analysis, 1,181 participants (50.5\%) completed TIPSA 2.0, and 1,158 (49.5\%) completed TIPSA 2.1.

\section{Analysis}

Mplus 7.4, a statistical software package equipped to run both exploratory and confirmatory factor analyses, was used to perform the data analyses (L. K. Muthén \& Muthén, 2015a). The weighted least squares (WLSMV) estimator was used, which is the default estimator in Mplus 7.4 for confirmatory factor analysis (CFA) with categorical data (L. K. Muthén \& Muthén, 2015b). Although maximum likelihood (ML) is often the preferred estimator, model fit measures that utilize this method for categorical data are often biased, therefore MLSMV is preferred (Brown, 2015; Yu, 2002).

As the data for this study was categorical in nature, assuring that each of the three subgroups had adequate information in each category was necessary prior to commencing analysis. The category percentages for all 53 items in each of the three subgroups appeared similar and thus adequate for commencement of analysis.

Initial confirmatory factor analysis (CFA). Both versions of the TIPSA, as updated by Skinner, were hypothesized to have a latent factor structure of five factors. This structure was based on the PTSD criteria from the DSM-5 (American Psychiatric Association, 2013), which suggests five key criteria for diagnosis. As such, a confirmatory factor analysis (CFA) of the TIPSA was conducted using all of the original items from the TIPSA in order to assesses the goodness-of-fit of the original Skinner Theoretical Model (Brown, 2015). 
Confirmatory factor analysis (CFA) examines the relationship between indicators (items) and factors (criteria). "CFA is almost always used during the process of scale development to examine the latent structure of a test instrument (e.g., a questionnaire). In this context, CFA is used to verify the number of underlying dimensions of the instrument (factors) and the pattern of item-factor relationships (factor loadings)" (Brown, 2015, p. 1)

Goodness-of-fit was determined by reviewing four separate indices. The first index to be considered was the root mean square error of approximation (RMSEA) which assesses how well a model reasonably fits a given population (Brown, 2015). Acceptable values for this index tend to hover around 0.05 . This index is reported to not function as precisely with small samples or in models with few degrees of freedom, though neither of these were a concern in the current study as sample size was sufficiently large, and there were no major constraints placed on the model. However, it has been noted in previous research that RMSEA can function differently with categorical data and may not be completely reliable.

The next indices are a pair of comparative fit indices: the comparative fit index (CFI); and the Tucker-Lewis index (TLI). These indices assess how well a model fits when compared to a baseline, or null, model. Both the CFI and the TLI endorse goodness-of-fit as their values approach 1.00 (Brown, 2015). An important difference between the two is that the TLI penalizes model complexity, as does the RMSEA. As such, the CFI is reported to perform better than either the TLI or the RMSEA, and as its cutoff value nears 0.96 it has acceptable rejection rates across samples greater than 250 (Yu, 2002).

The final index is a relatively new index called the weighted root mean square residual (WRMR). This index is reported to be suitable for models with categorical outcomes, in models where the variances of the sample statistics widely vary, and in models where the sample 
statistics might be on different scales. Generally a value between 0.95 and 1.00 is acceptable for the WRMR (Wang \& Wang, 2012; Yu, 2002). One benefit of the WRMR over the previous three statistics is that is has shown an increase in power as sample size increases.

Following the initial review of goodness-of-fit, the parameter estimates from the CFA were examined to identify items that might be adversely affecting model fit. As a first step, standardized factor loadings were examined. Comrey and Lee (2013) suggest that standardized factor loadings below 0.50 "cannot be relied upon to provide a very good basis for factor interpretation" (p. 243). They suggest retaining items with standardized loadings of at least 0.55 , or 30\% overlapping variance (Comrey \& Lee, 2013; Tabachnick \& Fidell, 2007).

At the same time, when homogeneity of scores is suspected (as was the case with scores on the TIPSA), retaining indicators with lower factor loadings may be advisable (Tabachnick \& Fidell, 2007). Applied research guidelines indicate that standardized factor loadings between 0.30 and 0.40 can operationally be considered salient to the model (Brown, 2015). Based on this information, it was determined that items with standardized factor loadings less than 0.40 , or $16 \%$ overlapping variance, would be removed from the model entirely, one at a time, beginning with the item with the lowest factor loading.

Finally, the modification indices (MIs), as reported in the Mplus output, were also examined. It is generally recommended that MIs only be used when "theoretical fit needs modification because of low fit statistics" (R. Larsen, personal communication, July 20, 2017). As this was the case in the current study, MIs were considered during model modification.

In practice, MIs larger than 4.00 are generally considered statistically significant (Brown, 2015; Keith, 2014; Wang \& Wang, 2012). However, MIs are sensitive to sample size; and as the sample size for this study was somewhat large, the MIs were quite large as well. In instances 
such as this, Brown (2015) advised that, "the size and direction of EPC [estimated parameter change] values should be considered in tandem with modification indices to assist in the determination of whether the respecification is conceptually and statistically viable" (p. 102). Thus, items with the large modification indices and high EPCs were considered for modification.

In addition to the statistical indications for modifications, the theoretical underpinnings of each item identified for removal were evaluated in order to determine whether the statistical suggestions should be followed (Brown, 2015; Wang \& Wang, 2012). This was done in order to help prevent "misspecification and overfitting" of the model (Brown \& Moore, 2012, p. 373), as can happen during model modification (also referred to as model specification search) if both empirical and statistical evidence is not considered (Liang, 2014). Once it was determined that goodness-of-fit was in acceptable ranges for all specified indices, revision of the TIPSA was completed and the resulting model was cross-validated with separate sub-samples.

CFA of alternative models. In addition to the Skinner theoretical model, an examination of a second-order factor model, where the five latent factors of the Skinner theoretical model loaded onto a second-order factor, was completed. This model was examined because of the high correlations between the five first-order factors in the Skinner model. In addition, a single-factor model, where all of the retained items were hypothesized to load onto a single latent factor, was also analyzed. Again, the decision to examine this model was informed by the high correlations between factors. Finally, a bifactor model was also considered. Once each model was analyzed, Chi-square difference testing was conducted to determine which of the four models provided the best goodness-of-fit for the data. 


\section{CHAPTER 4}

\section{Results}

The initial CFA of the Skinner model was the first analysis conducted, followed by the second-order model, the single-factor model, and the bifactor model. The O-CFA subsample was utilized for all three of these analyses. After the final preferred model was identified, two crossvalidation analyses were conducted using the EFA subsample and the E-CFA subsample.

\section{CFA on Skinner Model}

The first CFA was conducted on all 53 items from the TIPSA. Items were assigned to one of five factors as designated by the Skinner model, and all items were treated as categorical. Items 1 through 11 were assigned to Factor A (Exposure to Threat); items 12 through 21 to Factor B (Reliving the Event); items 22 through 24, and items 27 through 29 to Factor C (Avoidance); items 25 and 26, and items 30 through 40 to Factor D (Negative Cognition); and items 41 through 53 to Factor E (Emotional Arousal).

After executing the CFA, the fit statistics showed a lack of fit of the model to the data. RMSEA was 0.085 , CFI was 0.755 , TLI was 0.743 , and WRMR was 2.633 . However, the analysis also showed that the sample correlation between Items 23 and 24 was 1.00 . When this occurs, Mplus recommends that one of the items be removed from the model. In examining the category counts for the two items, Item 24 was found to be devoid of responses in the last two response categories, and was the only item without responses in all five categories. Empirically speaking, Item 24 did not appear to fit with the other indicators assigned to Factor C. Therefore, Item 24 was removed from the model and the CFA was rerun.

Again, fit criteria were not met. RMSEA was 0.086, CFI was 0.754, TLI was 0.742, and WRMR was 2.638. In terms of construct reliability, the Raykov's Rho estimate for Factor A was 
0.800, Factor B was 0.898 , Factor C was 0.705 , Factor D was 0.898 , and Factor E was 0.922. At this point, the initial CFA of the Skinner Model was deemed complete. However, due to the lack of significant fit statistics, it was determined to utilize a specification search in order to identify whether model fit might be improved. The respecification process is outlined below. The guidelines for the specification search were outlined previously in the method section.

\section{Model Respecification}

The output from the CFA indicated that seven items $(3,4,6,11,24,40,45 \mathrm{R})$ did not have significant factor loadings - all of the items had standardized loadings less than 0.400 . Accordingly, these seven items were removed from the model, and the analysis was run again using the remaining 46 items. The second analysis mirrored the first, and the output of this analysis again showed that the fit criteria were not met. RMSEA was 0.097, CFI was 0.745, TLI was 0.731 , and WRMR was 2.792. Two additional items (Item 9 - Factor A; Item 28 - Factor C) failed to load significantly. These items were removed, and the analysis was run again with 44 items loading on five factors.

The third analysis showed that all 44 items loaded significantly on their respective factors; however, the fit criteria remained unmet. RMSEA was 0.098, CFI was 0.752, TLI was 0.737, and WRMR was 2.767. The reliability estimate for Factor A was 0.797, Factor B was 0.898, Factor C was 0.695, Factor D was 0.905, and Factor E was 0.927.

At this point, the model modification indices (MIs) were examined to determine if any other items might be removed in order to achieve model fit. Mplus provides three types of MIs: ON/BY statements, which suggests possible cross-loadings of items; ON statements, which suggests possible regression coefficients; and WITH statements, which suggest correlated error 
terms between items. As we were not interested in adding regression coefficients to the model, only the ON/BY and WITH statements were used for model modification in this study.

Model modification utilizing ON/BY statements. Upon initial examination of the $\mathrm{ON} / \mathrm{BY}$ statements, criteria were set for the identification of problematic items. It was determined that items with an MI greater than 100 and a standardized estimated parameter change (sEPC) greater than 0.50 would be removed one at a time, beginning with the item with the highest MI. Once all items with an MI greater than 100 were removed, any remaining item with an SEPC greater than 1.00 would also be removed.

The first item identified with these criteria was Item 50, having three MIs greater than 200 and three associated sEPCs greater than 0.60. In examining the item, it was found to be quite vague in its wording ("I feel like I need to check up on my partner") and not obviously related to Factor E (Emotional Arousal). With this evidence, it was determined to remove Item 50. An improvement in fit criteria was observed after it was removed.

This analysis produced a new set of MIs that suggested Item 31 be the next item removed. Item 31 had three MIs greater than 200, and one greater than 100. Additionally, all associated sEPCs were above 0.5 . In reviewing Item 31 , it appeared to be highly related to Item 30 in its attempt to assess the partner's focus of blame for the addict's behavior; however, Item 31 was less specific in its wording than Item 30 . As such, Item 31 was removed from the model and the analysis was rerun. Again, improvements were seen in the fit criteria with the removal of this item.

The resulting MIs were examined, and Item 46 had an MI greater than 100 with an sEPC of 0.586. Item 46 (Factor E - Emotional Arousal) addressed a lack of focus and distraction ("I find it harder to focus on what is going on around me since I discovered my partner's behavior"), 
which is similar to Item 25 ("Since discovering my partner's behavior I get distracted easily"). Item 46 did not appear to fit as well with Factor E as Item 25 did with Factor D (Cognition and Negative Mood); therefore, Item 46 was removed as the next modification to the model.

Following the removal of Item 46, analysis outputs showed that Item 47 ("I find that I lose things since I learned of my partner's behaviors") had two MIs over 100 and one sEPC greater than 0.6. This item did not appear to fit well with Factor E either, and was also quite similar to Item 25. Consequently, Item 47 was removed from the model as well, and resulting fit statistics continued to show improvement.

After removing Item 47, no other items showed MIs greater than 100. However, Item 27 did have an sEPC greater than 1.0. This item was written to assess avoidance behavior associated with public places. All items on Factor C addressed some type of avoidance behavior, and as Item 27 ("I avoid going to places or locations where people could be dressed scantily") did not appear to add significant information, it was removed as well. Following removal of this item, no other items met the established criteria for problematic items. Subsequently, attention was turned to the WITH statements in the Mplus output.

Modification utilizing WITH statements. When inspecting the WITH statements, item pairs with MIs greater than 100 and sEPCs greater than 0.30 were flagged as problematic. The relationship between Items 52 and 53 had an MI over 680, and an sEPC greater than 0.50 . In examining the items, both address self-harm as a component of emotional arousal (Factor E). Item 52 was more specific, asking about suicidal ideation, and Item 53 asked about general selfharm. The factor loadings for the items were also nearly identical. Therefore, rather than allowing for a correlated error term in the model, it was decided to remove Item 53 and retain 
Item 52 since. This decision followed the precedent set by removing Item 31 (general) and leaving Item 30 (specific).

Items 42 and 43 were the next identified for possible modification; The MI was over 470, and the sEPC was greater than 0.40. Both items loaded onto Factor E (Emotional Arousal), and their loadings were within 0.002 of each other. In examining the items, Item 42 dealt with responses of anger, whereas Item 43 dealt with being critical in conversations. The items were just different enough that it was decided to retain both items and, for the time being, refrain from allowing the error terms to correlate.

The next highest MI was for the relationship between Items 48 and 49. The MI was above 200, and the sEPC above 0.35 . Item 48 addressed monitoring of behaviors, and Item 49 addressed reading of emotions. Again, the items were different enough that it was decided to retain both items and refrain from allowing correlated error terms.

Items 37 and 38 were identified as the next problematic pair. In this instance, Item 37 asked about not belonging in social settings, and Item 38 asked about feeling different than others. These two items appeared similar enough that Item 38, the more general of the two, was removed rather than allowing the error terms to correlate, and the revised model was analyzed.

The resulting MIs identified did not identify any other problematic items other than those already identified above. As the fit criteria were still below the desired values, it was determined to allow the error terms for Items 42 and 43 to correlate since the MI was still over 470, and the sEPC above 1.0. Following the addition of a WITH statement for Items 42 and 43, the MI and sEPC for Items 48 and 49 were still high enough to suggest they be allowed to have correlated error terms as well. 
After modifying the model to include a WITH statement for Items 48 and 49, no other MIs met the criteria established at the beginning of the modification process. However, Items 18 and 19 had an MI over 100 and an sEPC just under 0.30. Although the sEPC was lower than the initial criteria, an examination of the questions identified that the items were assessing similar constructs (sensitivity to types of images displayed in public), and it made theoretical sense to allow the two error terms to correlate.

This addition to the model resulted in a positive increase in the values for the fit criteria. RMSEA was 0.062, CFI was 0.910, TLI was 0.902, and WRMR was 1.616. These values were deemed high enough to consider the model to be of adequate fit for the data according to traditional rule-of-thumb cutoffs $(\mathrm{RMSEA}<0.08, \mathrm{CFI}>0.90, \mathrm{TLI}>0.90, \mathrm{WRMR}<1.00)($ Wang $\&$ Wang, 2012), and no other modifications were made.

The final respecificed model retained all five of the original factors: Factor A (Items 1, 2, 5, 7, 8, 10); Factor B (Items 12 - 21, correlated error between Items 18 and 19); Factor C (Items 22, 23, 29); Factor D (Items 25, 26, 30, 32 - 37, 39); and Factor E (Items 41 - 44, 48, 49, 51, 52, correlated errors between Items 42 and 43, and Items 48 and 49). The reliability (Rho) estimates for the factors were as follows: Factor A was 0.798; Factor B was 0.894; Factor C was 0.701; Factor D was 0.873; and Factor E was 0.860. The final model is displayed in Figure 1.

Second-order factor model. Given the high correlations between the latent factors in the five-factor model, a second-order factor (Trauma) was added to the resultant model to determine whether this factor would improve goodness-of-fit. The fit statistics for the second-order model were nearly identical to the first-order model. RMSEA was 0.063, CFI was 0.908, TLI was 0.901, and WRMR was 1.643. This model is displayed in Figure 2. 
Single-factor model. Following the analysis of the second-order factor model, a single factor model was analyzed, using the indicators from the original 5-factor model. The fit statistics for this model appeared to be worse than those for the previous two models. RMSEA was 0.075 , CFI was 0.866 , TLI was 0.858 , and WRMR was 1.935 ; and the reliability estimate for Trauma was 0.954. This model is displayed in Figure 3.

Bifactor model. The final model to be analyzed was a bifactor model, which combined both the 5-factor and single-factor models. In a bifactor model, all of the factor correlations are constrained to 0.00 . With that constraint, however, the analysis resulted in a warning stating that the variable covariance matrix was not positive definite. An examination of the resulting correlation matrix showed that Item 22 correlated with Factor $\mathrm{C}$ at 2.125 . When a correlation is estimated at greater than 1.00 , it is generally an indication that the item and the factor are indistinguishable, and that the model is not appropriate for the data (B. O. Muthén, 2011, Mar 18). Despite the warning, the model estimation terminated normally, and did produce fit statistics. RMSEA was 0.061, CFI was 0.918, TLI was 0.907, and WRMR was 1.511 . The These values were nearly identical to those from the original CFA model.

As Item 22 did not produce errors in the covariance matrices of the other models, it was assumed that the correlations between the factors accounted for the indistinguishable relationship between Item 22 and Factor C. Therefore, the bifactor model was dismissed as a viable model for the TIPSA at this point in time. This model is displayed in Figure 4.

\section{Comparison of Models}

The four models described above were nested models. The Bifactor model was the least restrictive, followed by the 5-factor model, the second-order factor model, and finally the singlefactor model. In order to identify which of these models should be retained as the preferred 


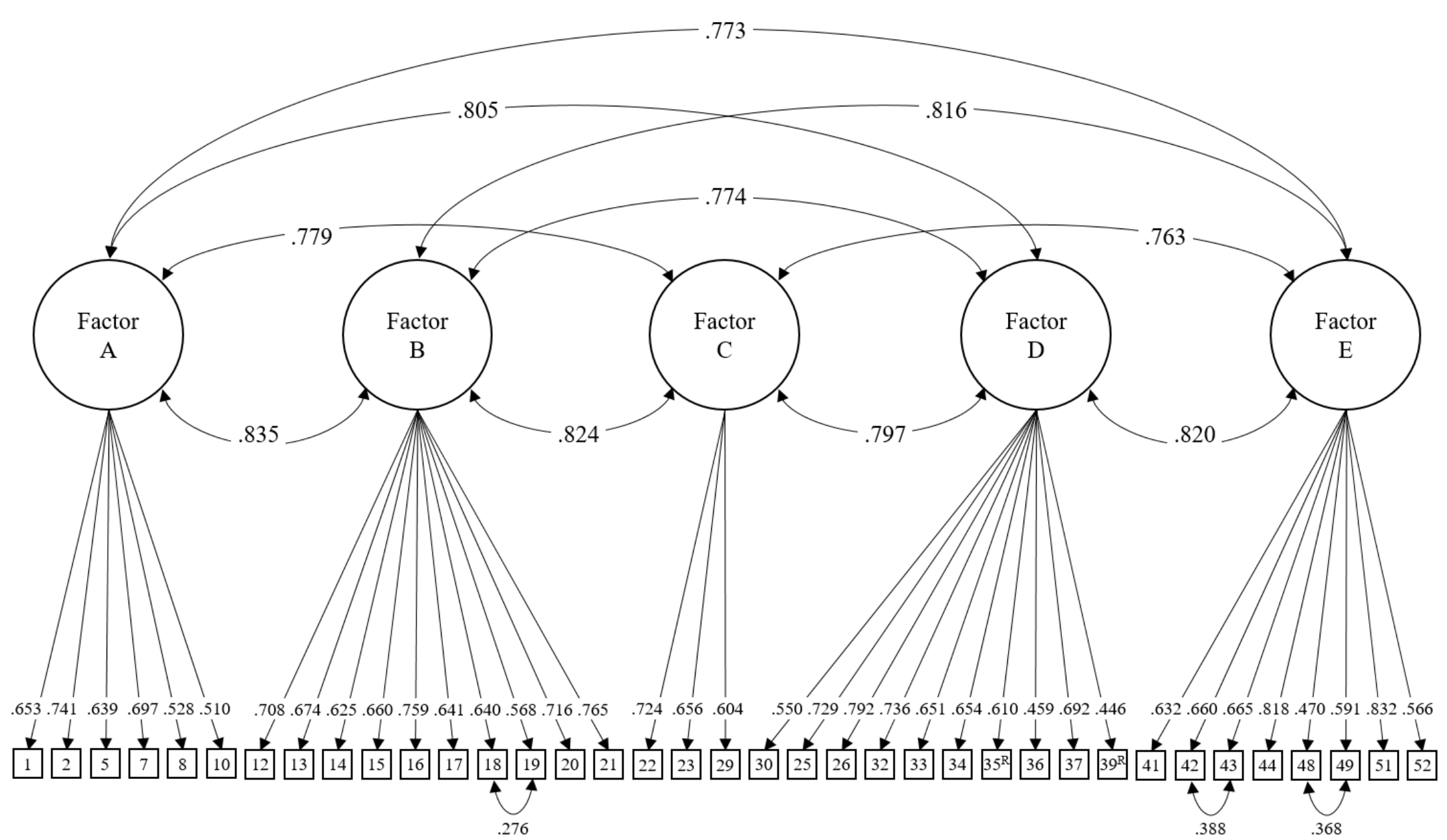

Figure 1. 5-factor Model with original data. 


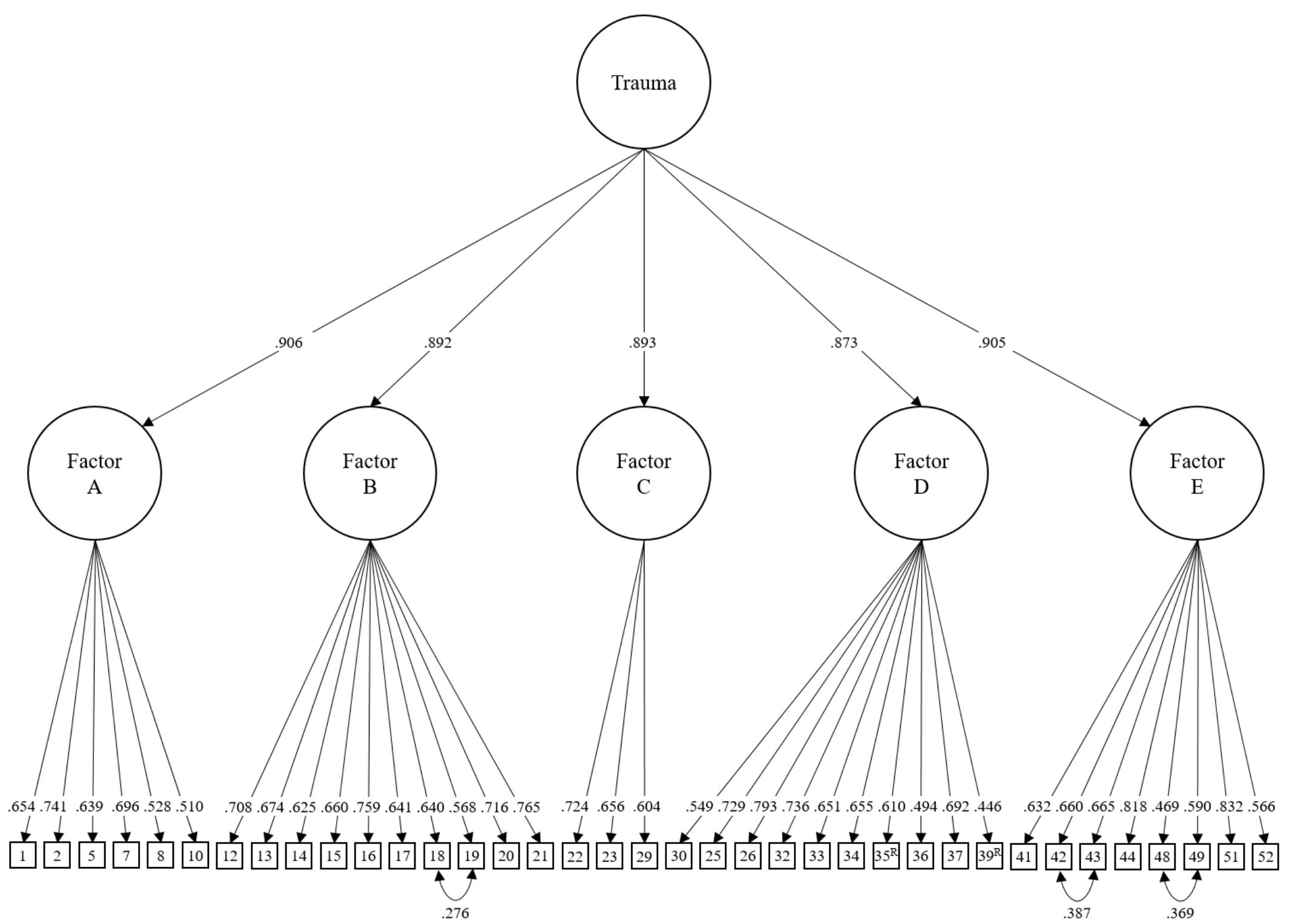

Figure 2. Second-order Factor Model with original data. 


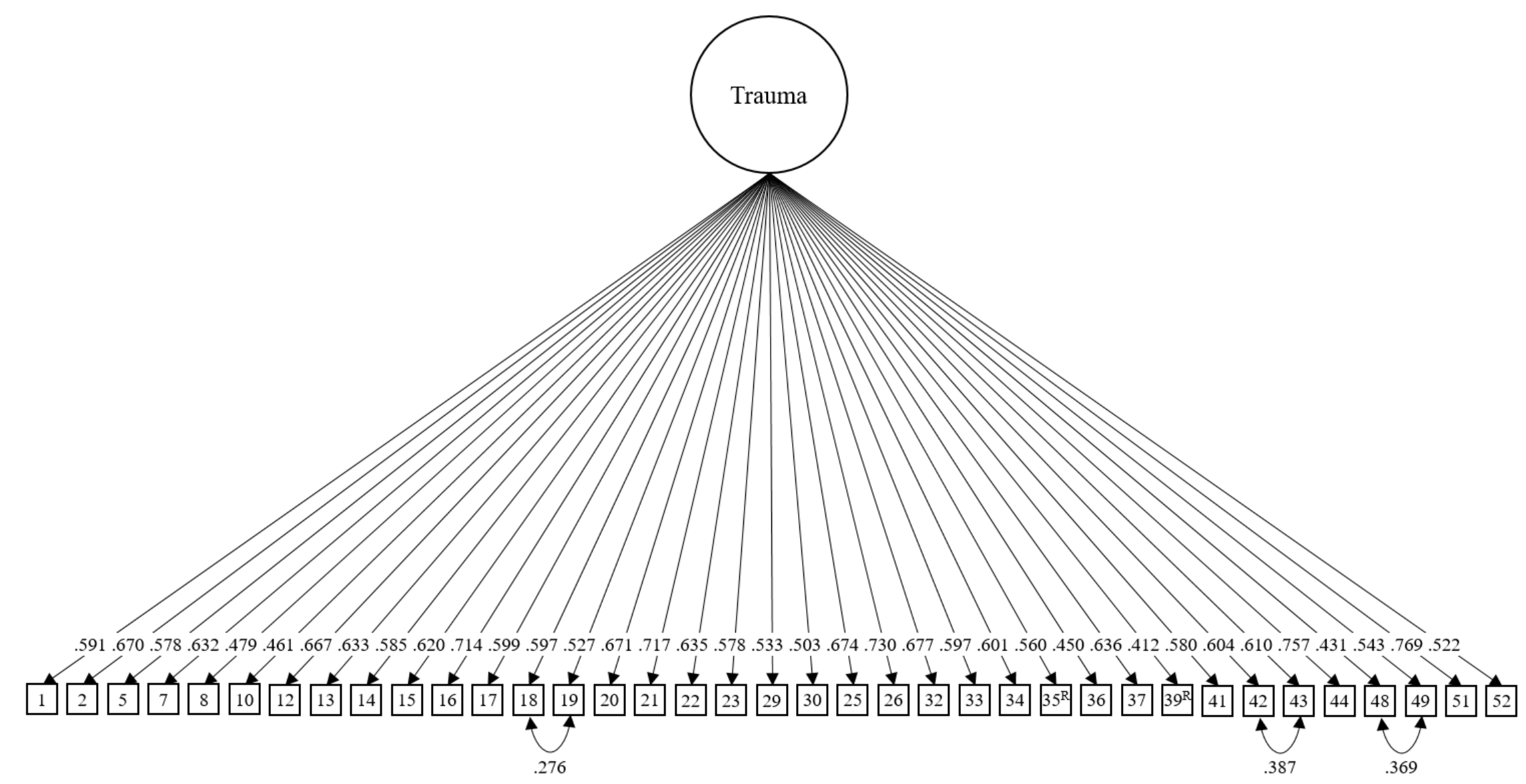

Figure 3. Single General-factor Model with original data. 


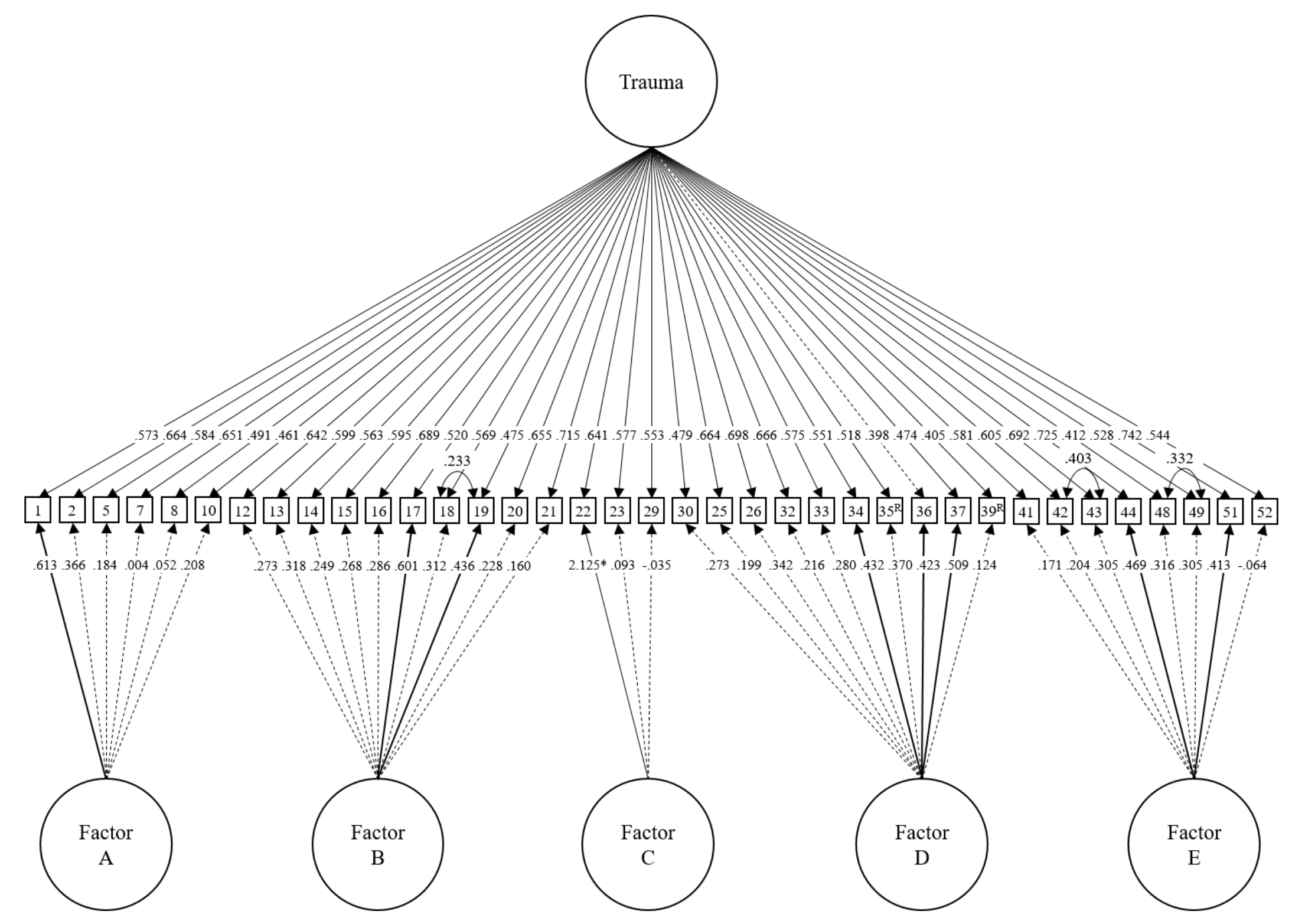

Figure 4. Bifactor Model with original data. 
model, the Mplus Chi-Square Test for Difference Testing (DIFFTEST) was used. Because the bifactor model did not produce a nonsingular matrix, due to the correlation between Item 22 and Factor $\mathrm{C}$, and as it had already been dismissed as a viable option, it was not included in the model comparison testing.

According to the results of the comparison testing, the original CFA model had the best fit with the data. A summary of the fit statistics for each model are included in Table 3, and the results of the comparison tests are included in Table 4.

Table 3

Fit Statistics for All Four Models

\begin{tabular}{lrrrr}
\hline Fit Statistics & 5-Factor & Second-Order & General Factor & Bifactor* \\
\hline$\chi^{2}$ & $2,481.220$ & $2,529.764$ & $2,881.605$ & $2,289.313$ \\
RMSEA & 0.062 & 0.063 & 0.071 & 0.061 \\
CFI & 0.910 & 0.908 & 0.887 & 0.918 \\
TLI & 0.902 & 0.901 & 0.879 & 0.907 \\
WRMR & 1.616 & 1.643 & 1.795 & 1.511 \\
\hline
\end{tabular}

*Covariance Matrix was not positive definite

Table 4

DIFFTEST Results of 5-factor Model Compared to Other Models, with Original Data

\begin{tabular}{lccc}
\hline & Second-Order & General Factor & Bifactor \\
\hline Value & 51.052 & 583.623 & Singular \\
df & 5.000 & 10.000 & Covariance \\
P-Value & 0.000 & 0.000 & Matrix \\
\hline
\end{tabular}

\section{CFA of Models Using Collapsed Category Data}

In his recent dissertation, Stokes (2017) conducted an item analysis of each item contained in the TIPSA. Based on his results, he produced recommendations for collapsing categories and rescoring certain items. Following his recommendations, the TIPSA scores for the Original-CFA subsample were rescored, and the four models (5-factor, second-order factor, 
single general-factor, and bifactor) were reanalyzed using the modified scores. Table 5 shows which items were rescored and the resultant number of response categories.

Table 5

Item Rescoring (Collapsed Response Categories)

\begin{tabular}{cccccc}
\hline Item & $\begin{array}{c}\text { \# of Original } \\
\text { Categories }\end{array}$ & $\begin{array}{c}\text { \# of Collapsed } \\
\text { Categories }\end{array}$ & Item & $\begin{array}{c}\text { \# of Original } \\
\text { Categories }\end{array}$ & $\begin{array}{c}\text { \# of Collapsed } \\
\text { Categories }\end{array}$ \\
\hline 1 & 5 & N/A & 28 & 5 & N/A \\
2 & 5 & N/A & 29 & 5 & N/A \\
3 & 5 & 2 & 30 & 5 & 3 \\
4 & 5 & 4 & 31 & 5 & 3 \\
5 & 5 & 4 & 32 & 5 & 2 \\
$6^{\mathrm{R}}$ & 5 & 2 & 33 & 5 & 3 \\
7 & 5 & 3 & 34 & 5 & N/A \\
8 & 5 & 3 & $35^{\mathrm{R}}$ & 5 & 3 \\
9 & 5 & 3 & 36 & 5 & 3 \\
10 & 5 & 3 & 37 & 5 & 3 \\
11 & 5 & 3 & 38 & 5 & 2 \\
12 & 5 & 4 & $39^{\mathrm{R}}$ & 5 & N/A \\
13 & 5 & 4 & 40 & 5 & 2 \\
14 & 5 & 2 & 41 & 5 & 2 \\
15 & 5 & 3 & 42 & 5 & 2 \\
16 & 5 & N/A & 43 & 5 & 4 \\
17 & 5 & N/A & 44 & 5 & N/A \\
18 & 5 & N/A & $45^{\mathrm{R}}$ & 5 & 3 \\
19 & 5 & 4 & 46 & 5 & 3 \\
20 & 5 & 4 & 47 & 5 & 2 \\
21 & 5 & 2 & 48 & 5 & 4 \\
22 & 5 & N/A & 49 & 5 & \\
23 & 5 & N/A & 50 & 5 & 5 \\
24 & 5 & 3 & 51 & 5 & 5 \\
25 & 5 & N/A & 52 & 53 & \\
26 & 5 & 3 & & 5 & \\
27 & 5 & & & 5 & 2 \\
\hline
\end{tabular}

The respecified 5-factor model was examined first, and the results of the analysis showed that Item 32 with its collapsed categories was problematic. This item was removed from the model, and the analysis rerun. The resulting fit statistics with rescored data were improved from the fit statistics obtained with the original data. RMSEA was 0.056, CFI was 0.927, TLI was 0.921, and WRMR was 1.555. 
The other three models were then analyzed using the rescored data, and the fit statistics for the second-order factor model and the general factor model improved significantly. However, the Bifactor model would not converge with the rescored data. The resulting fit criteria values are reported in Table 6. The DIFFTEST function was again used to compare the four models. The results from the comparison testing are reported in Table 7, and the three models which converged are displayed in Figures 5 through 7.

Table 6

Fit Statistics for All Four Models with Rescored Data (without Item 32)

\begin{tabular}{lcrrr}
\hline Fit Statistics & Bifactor & 5-Factor & Second-Order & General \\
\hline$\chi^{2}$ & No & $2,002.155$ & $2,033.353$ & $2,742.642$ \\
RMSEA & Convergence & 0.056 & 0.056 & 0.068 \\
CFI & & 0.927 & 0.926 & 0.890 \\
TLI & & 0.921 & 0.920 & 0.883 \\
WRMR & & 1.555 & 1.579 & 1.873 \\
\hline
\end{tabular}

Table 7

DIFFTEST Results of 5-factor Model Compared to Other Models, with Rescored Data

\begin{tabular}{lcrc}
\hline & Second-Order & General & Bifactor \\
\hline Value & 35.733 & 415.797 & No \\
df & 5.000 & 5.000 & Convergence \\
P-Value & 0.000 & 0.000 & \\
\hline
\end{tabular}

\section{Preferred Model}

Following the analyses of all of the models with both the original and the rescored data, the 5-factor model appeared to be the best model based on the statistical evidence. In addition, the 5-factor model aligned with the hypothesized factor structure of the TIPSA. However, in practice, trauma is operationally defined as a single, overarching concept, rather than by its five, individual diagnostic categories. In this sense, the general-factor model seems to be the better fit 


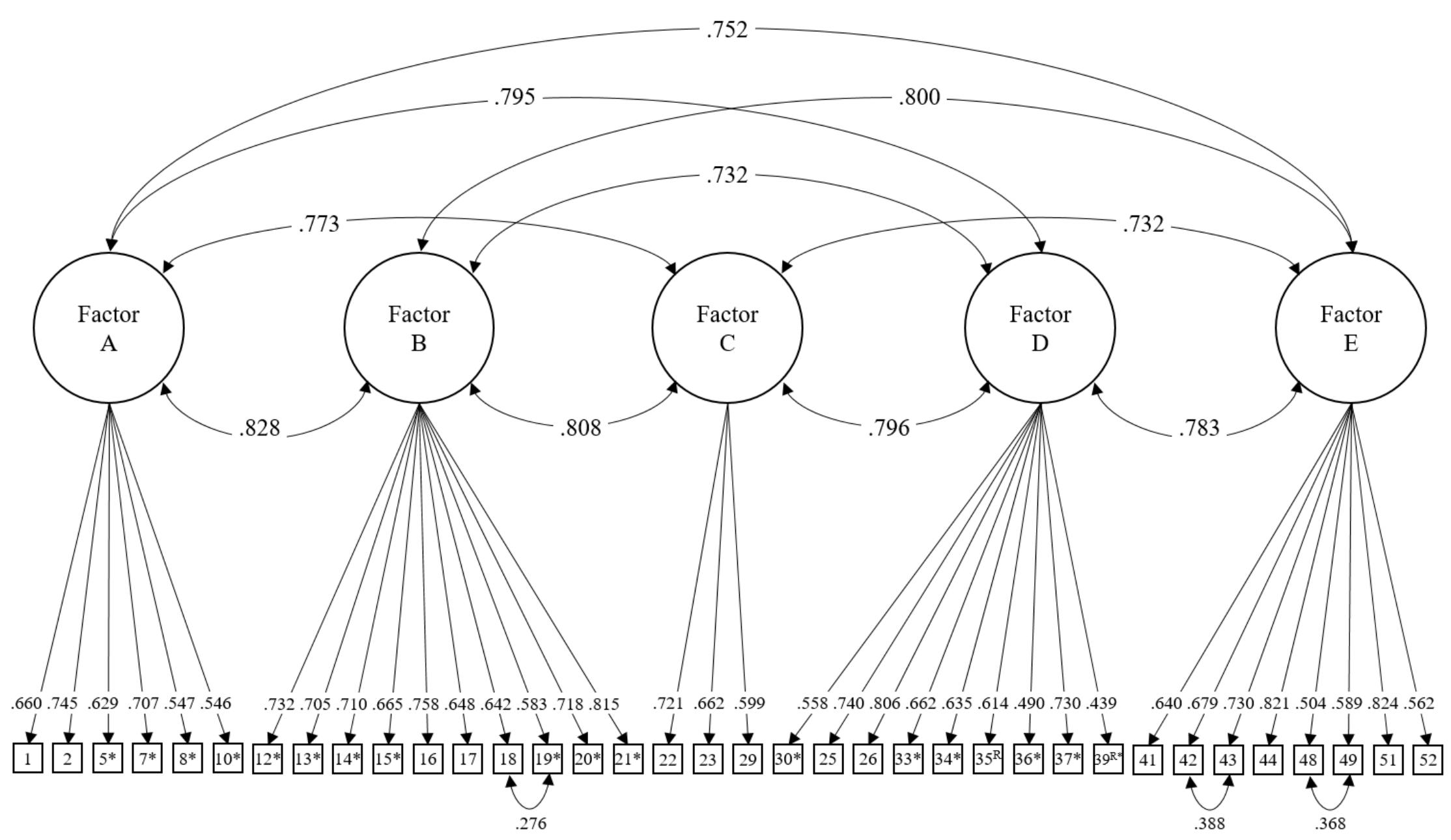

Figure 5. 5-factor Model with rescored data. 


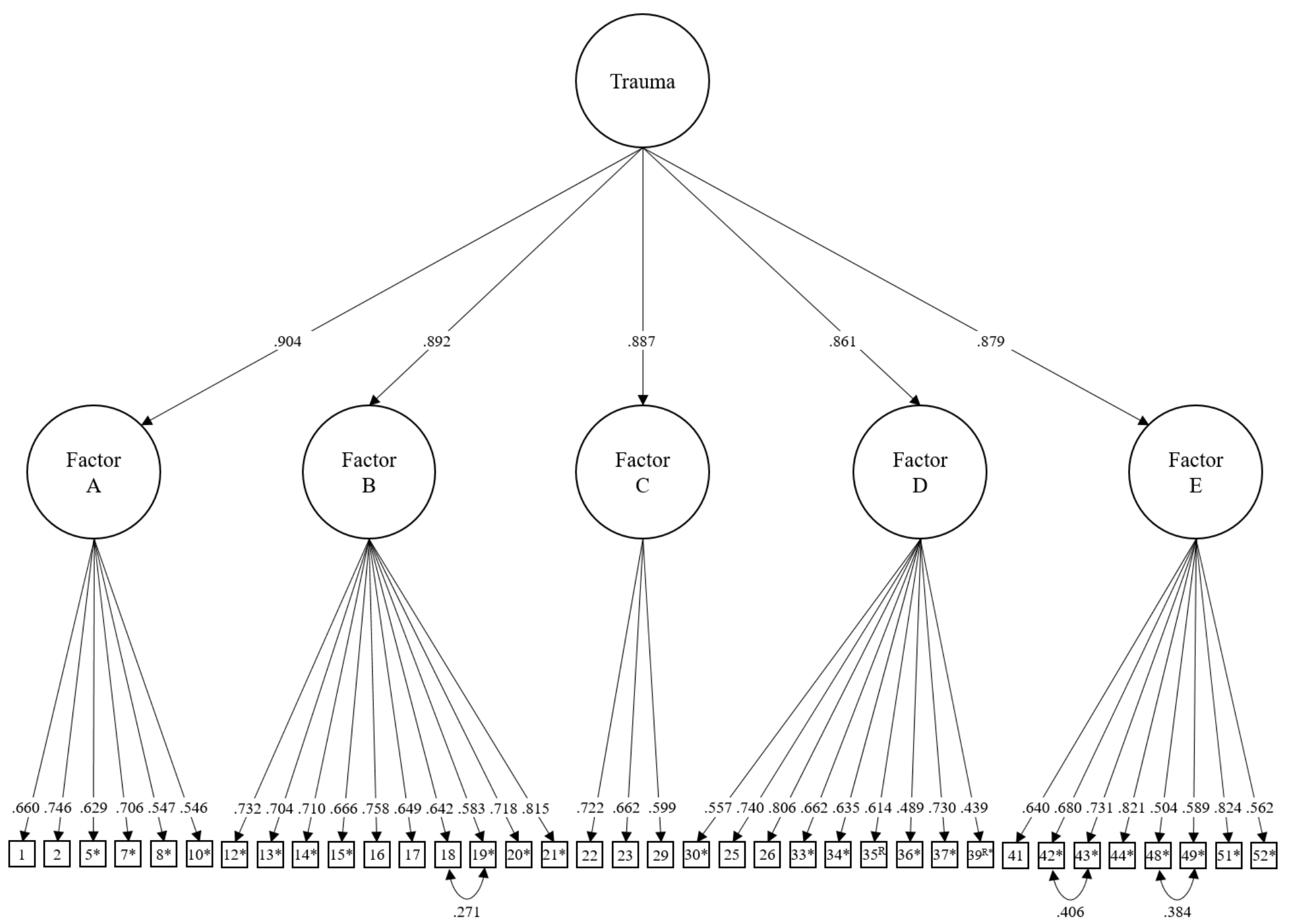

Figure 6. Second-order Factor Model with rescored data. 


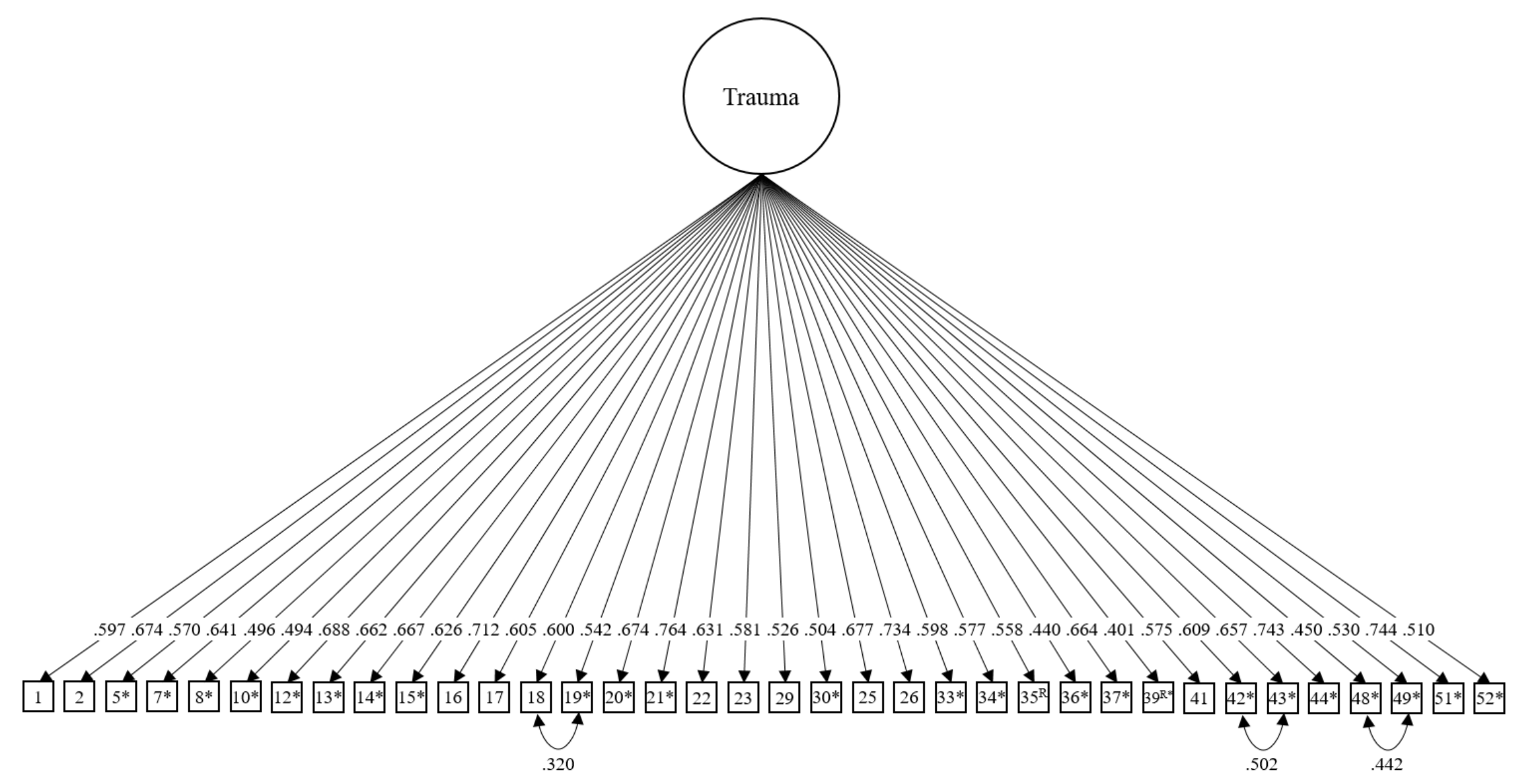

Figure 7. Single General-factor Model with rescored data. 
to the theoretical underpinnings of the TIPSA. Furthermore, the addition of a second-order factor provides a clearer understanding of the relationship and high correlation between the five firstorder factors. Thus, in order to account for both the statistical findings and the practical application of the TIPSA, the second-order factor model was identified as the preferred model.

\section{Cross-validation of Second-order Factor Model}

Cross-validation, utilizing both the CV1 and CV2 subsamples, was completed as the final step in the examination of the TIPSA's factor structure. The second-order factor model was applied to both the original data and the rescored data of each of the two subsamples. Results of the cross-validation showed consistent fit criteria values across samples. This suggests that the second-order factor model is not over-fit to the original data set. The fit statistics from the crossvalidation analyses are shown in Table 8 .

Table 8

Cross-validation Fit Criteria Comparisons for Second-order Model

\begin{tabular}{|c|c|c|c|c|c|c|}
\hline \multirow[b]{2}{*}{ Fit } & \multicolumn{3}{|c|}{ Original Data } & \multicolumn{3}{|c|}{ Rescored Data (without Item 32) } \\
\hline & CFA & CV1 & CV2 & CFA & CV1 & CV2 \\
\hline Statistics & Sub Sample & Sub Sample & Sub Sample & Sub Sample & Sub Sample & Sub Sample \\
\hline$\chi^{2}$ & $2,529.764$ & $\overline{2,467.678}$ & $\overline{2,757.184}$ & $2,033.353$ & $\overline{2,071.181}$ & $2,331.371$ \\
\hline RMSEA & 0.063 & 0.062 & 0.066 & 0.056 & 0.055 & 0.059 \\
\hline CFI & 0.908 & 0.910 & 0.913 & 0.926 & 0.928 & 0.925 \\
\hline TLI & 0.901 & 0.904 & 0.907 & 0.920 & 0.923 & 0.920 \\
\hline WRMR & 1.643 & 1.609 & 1.685 & 1.579 & 1.573 & 1.681 \\
\hline
\end{tabular}

\section{CHAPTER 5}

\section{Discussion}

\section{The Second-order Factor Model}

Post-traumatic Stress Disorder (PTSD), as described in DSM-5 (American Psychiatric Association, 2013), has five core criteria that must be met in order for a diagnosis to be given. 
These criteria are: (a) Exposure to Trauma; (b) Reexperiencing the Trauma; (c) Avoidance of Trauma-related Stimuli; (d) Negative Thoughts or Feelings; and (e) Trauma-related Arousal and Reactivity. Each item on the TIPSA was identified by the author as relating to one of these criteria. Thus, at the beginning of this study, it was hypothesized that a 5-factor model would be the preferred model to fit the TIPSA data.

Through the course of analysis, the 5-factor model emerged as the statistically-preferred factor structure for the TIPSA. However, the second-order factor model also yielded robust fit statistics results, which, upon visual inspection, were nearly identical to those of the 5-factor model. The inclusion of a second-order factor also appeared salient to the TIPSA's alignment with the PTSD criteria, as each of the criteria is designed to ultimately support the presence of trauma. Thus, these findings are theoretically consistent with the intended purpose of the TIPSA, which is to measure the presence of trauma in the context of discovery or disclosure of a partner's sexual addiction.

\section{Parsimony of the TIPSA}

Over the course of model modification, the TIPSA was reduced from 53 items to 36 items. With the removal of each item, goodness-of-fit increased for the model as a whole. Crossvalidation indicated that this reduced model was not due to chance alone; and that the model was not overfit to the original subsample. The final model did allow for three correlated error terms, which statistically increases the complexity of the instrument. However, as these statements do not directly affect the administration of the TIPSA, their presence does not impact the ease with which the assessment is administered. 


\section{Recommendations for Revision of the TIPSA}

Removal of items. Seven items were removed after the first round of CFA due to low factor loadings. These were Items $3,4,6,11,24,40$, and $45^{\mathrm{R}}$. In his item analysis of the TIPSA, Stokes (2017) also identified Items $6,11,40$, and $45^{\mathrm{R}}$ as poorly functioning items. Item 6 addressed safety; Item 11 focused on previous life experience; Item 40 asked if blame should be placed on society; and Item $45^{\mathrm{R}}$ addressed feelings of calmness since the discovery of the partner's behaviors. As none of these four items appears critical to their respective factors, and as they appear to function poorly in general, it is recommended they be removed from the TIPSA.

In addition, Item 3 ("My partner threatens to hurt me in some way if I do not comply with his/her sexual fantasies") is also recommended for removal. Along with a low factor loading, Stokes (2017) found that Item 3 functioned well only after collapsing the response categories to a binary option. The combination of findings suggests that this item should not be included in the TIPSA.

Revision of items. Items 4 and 24 were removed from the model based on their factor loadings. Item 4 asked about potential for physical harm, and Item 24 queried about sexual contact with the partner. In his study, Stokes (2017) found that the items functioned well after collapsing their response categories. Therefore, it is recommended that these items be revised rather than removed.

Items 9, 27, and 28 were also removed for low factor loadings; however, these items loaded above 0.40 until the first seven items were removed. Item 9, like Items 3 and 4 , was concerned with physical harm. It was also identified by Stokes (2017) as an item that functioned well after collapsing its response categories. With Items 3, 4, and 9 all removed from the model, the aspect of physical harm from others appeared under-represented. Therefore, it is 
recommended that Item 9, along with Item 4, be revised and retained as part of the TIPSA. Items 27 and 28, which assessed proactive avoidance, are discussed further in the next section regarding the revision of Factor $\mathrm{C}$.

It is also recommended that the three pairs of items with correlated errors terms be considered for revision. All six items (Items 18, 19, 42, 43, 48, and 49) had high factor loadings within the model; however, the correlated error terms suggested that the item pairs were related beyond their inclusion on the same factors. In addition, Items 37 and 38, and Items 52 and 53 could have been allowed correlated errors in the model, but Items 38 and 53 were removed from the model instead. Further examination of these 10 items by the TIPSA's authors may provide insight into removal or revision of specific items.

Revision of Factor C. Items 24 and 28, which were removed for low factor loadings, and Item 27, which was removed for potential cross-loadings, were initially assigned to Factor C. This factor turned out to be the smallest factor in the model, with only 3 items remaining in the final model. The items that were retained on this factor also had somewhat high potential crossloadings and correlated errors. In addition, in the absence of correlated factors, Item 22 was highly correlated with Factor C, preventing and in-depth analysis of the bifactor model. It is therefore recommended that Item 22, and at least one of the three removed items, be revised and returned to the model. Ideally, all six of the items created for this factor would be revised.

Revision of item order. In its current form, the TIPSA groups items according to the PTSD criteria they assess, with highly-related items often appearing adjacently to each other. It would be preferable to place items randomly throughout the instrument in order to avoid priming or biasing effects. Doing this might also allow some items which were previously discarded to be retained, and included correlated error terms to be removed. If the TIPSA remains an online 
instrument, the randomization of the presentation of items for each individual respondent should be considered.

Original versus collapsed response categories. Based on the fit statistics, the preferred model appeared to fit the rescored collapsed-category data better than the original data. However, in his research, Stokes (2017) found that TIPSA scores computed from the original categories were highly correlated with the scores computed from the collapsed categories. Because some of the collapsed categories created binary outcomes, and because an additional item had to be removed in order for the model to fit with the rescored data, it is recommended that the original response categories be used for scoring current the current TIPSA.

\section{Limitations}

While the evidence presented suggests that the second-order factor model provides the best theoretical and statistical fit for the TIPSA, there were indications that a bifactor model might also fit the data well. However, that hypothesis remains unsubstantiated due to both the high correlation between Item 22 and Factor $\mathrm{C}$ with the original data, and the lack of model convergence with the collapsed category data.

In addition, the items identified as having significant correlated error terms were all adjacent items. Because of this, the correlated errors may have been due to proximity, rather than another relationship. Thus, some of the items removed from the model due to significant correlated error terms may have been discarded inadvertently, and the added correlated error terms may not be necessary or accurate.

Finally, the respecified model was created utilizing specification searches in order to improve model fit. Using this method can result in overspecified models. In order to minimize 
this effect, boundaries for salient specifications were set in the method section; and the resultant model was subject to cross-validation.

\section{Suggestions for Future Research}

Moving forward, there are several areas of research regarding the TIPSA that could bolster the knowledge and literature base in this area. The first suggestion is to examine the factor structure of the TIPSA beginning with bifactor Exploratory Factor Analysis (EFA). This study examined the correlated factors structure according to the hypothesis of the authors of the TIPSA. However, the bifactor model is gaining traction in the psychometric community, and evaluating the TIPSA utilizing a bifactor model is recommended (see Canivez, 2016; Reise, 2012; Reise, Bonifay, \& Haviland, 2013; Rodriguez, Reise, \& Haviland, 2016).

The next recommendation is to conduct a convergent validity study. There are many valid and reliable assessments for PTSD, including a brief checklist published by the National Institutes of Mental Health (NIMH). As the TIPSA is also designed to measure PTSD, administering the NIMH PTSD Checklist (or another validated PTSD measure) along with the revised TIPSA, and then correlating the responses and scores between the two assessments, will help establish the construct validity of the TIPSA.

A discriminant validity study is also suggested. This study could be combined with the convergent validity study, or conducted independently. While many different measures and instruments could be used to assess divergent validity, it would be interesting, as well as pertinent to this field of study, to use a codependency measure to establish divergent validity. One of the primary purposes of the TIPSA is to show that partners of sex addicts experience trauma, rather than codependency. Thus, a discriminant validity study of this nature would 
provide evidence that the difference between codependency and PTSD is measurable among partners of sex addicts.

An in-depth examination of the invariance of the TIPSA is another possible study. Preliminary findings from this study suggest that the TIPSA may not function the same across subgroups of the sample. Of particular interest in a future study would be invariance between male and female respondents, as well as for respondents who have a current or previous diagnosis of PTSD. Other groups of interest may include religion, relationship status, and length of time since the disclosure or discovery of the addiction.

Finally, the TIPSA in its current state appears to provide only screening information regarding trauma in the context of sexual addiction. As awareness of the Trauma Model spreads, there may be a need for a more evaluative assessment. Therefore, exploring the possibility of revising the TIPSA to be used as an outcome assessment, in addition to a screening instrument, is advised. 


\section{References}

Alcoholics Anonymous. (2001). Alcoholics Anonymous: The story of how many thousands of men and women have recovered from alcoholism (4th ed.). New York, NY: A. A. World Services.

American Psychiatric Association. (2000). Diagnostic and statistical manual of mental disorders (4th ed., text rev.). Washington, DC: Author.

American Psychiatric Association. (2013). Diagnostic and statistical manual of mental disorders (5th ed.). Washington, DC: Author.

Anders, S. L., Frazier, P. A., \& Frankfurt, S. B. (2011). Variations in Criterion A and PTSD rates in a community sample of women. Journal of Anxiety Disorders, 25(2), 176-184. doi:10.1016/j.janxdis.2010.08.018

Anderson, S. C. (1994). A critical analysis of the concept of codependency. Social Work, 39(6), 677-685.

Baird, M. H. (2011). What can the twelve steps do for me? In S. Carnes (Ed.), Mending a shattered heart: A guide for partners of sex addicts (2nd ed.). Carefree, AZ: Gentle Path Press.

Beattie, M. (1987). Codependent no more. Center City, MN: Hazelden Foundation.

Briere, J. N., \& Scott, C. (2015). Principles of Trauma Therapy: A Guide to Symptoms, Evaluation, and Treatment (DSM-5 Update) (2nd ed.). Thousand Oaks, CA: Sage Publications, Inc.

Brown, T. A. (2015). Confirmatory factor analysis for applied research (2nd ed.). New York, NY: The Guilford Press. 
Brown, T. A., \& Moore, M. T. (2012). Confirmatory Factor Analysis. In R. H. Hoyle (Ed.), Handbook of structural equation modelling (pp. 361-379). New York, NY: Guilford Press.

Canivez, G. L. (2016). Bifactor modeling in construct validation of multifactored tests: Implications for understanding multidimensional constructs and test interpretation. In K. Schweizer \& C. DiStefano (Eds.), Principles and Methods of Test Construction: Standards and Recent Advances. Boston, MA: Hogrefe Publishing.

Carnes, S. (2011). What is sex addiction? In S. Carnes (Ed.), Mending a shattered heart: A guide for partners of sex addicts. Carefree, AZ: Gentle Path Press.

Carnes, S., \& O'Connor, S. (2016). Confirmatory analysis of the partner sexuality survey. Sexual Addiction \& Compulsivity, 23(1), 141-153. doi:10.1080/10720162.2015.1039151

Cermak, T. L. (1991). Co-addiction as a disease. Psychiatric Annals, 21(5), 266-272.

Comrey, A. L., \& Lee, H. B. (2013). A first course in factor analysis (2nd ed.). Hillsdale, NJ: Lawrence Elrbaum Associates.

Corley, M. D., \& Schneider, J. P. (2002). Disclosing secrets: Guidelines for therapists working with sex addicts and co-addicts. Sexual Addiction \& Compulsivity, 9, 43-67.

Corley, M. D., Schneider, J. P., \& Hook, J. N. (2012). Partner reactions to disclosure of relapse by self-identified sexual addicts. Sexual Addiction \& Compulsivity, 19, 265-283. doi:10.1080/10720162.2012.712022

Ferree, M. C. (2002). Sexual addiction and co-addiction: Experiences among women of faith. Sexual Addiction \& Compulsivity, 9(4), 285-292. doi:1080/10720160290062374 
Giordano, A. L., Prosek, E. A., Stamman, J., Callahan, M. M., Loseu, S., Bevly, C. M., . . . Chadwell, K. (2016). Addressing trauma in substance abuse treatment. Journal of Alcohol and Drug Education, 60(2), 55-71.

Grant, J. E., Potenza, M. N., Weinstein, A., \& Gorelick, D. A. (2010). Introduction to behavioral addictions. The American Journal of Drug and Alcohol Abuse, 36(5), 233-241. doi:10.3109/00952990.2010.491884

Harkness, D., Swenson, M., Madsen-Hampton, K., \& Hale, R. (2001). The development, reliability, and validity of a clinical rating scale for codependency. Journal of Psychoactive Drugs, 33(2), 159-171.

Hentsch-Cowles, G., \& Brock, L. J. (2013). A systemic review of the literature on the role of the partner of the sex dddict, treatment models, and a call for research for systems theory model in treating the partner. Sexual Addiction \& Compulsivity, 20(4), 323-335. doi:10.1080/10720162.2013.845864

Kafka, M. P. (2010). Hypersexual disorder: a proposed diagnosis for DSM-V. Archives of Sexual Behavior, 39(2), 377-400. doi:10.1007/s10508-009-9574-7

Keith, T. Z. (2014). Multiple regression and beyond: An introduction to multiple regression and structural equation modeling. . New York, NY: Routledge.

King, S. (2003). The impact of compulsive sexual behaviors on clergy marriages: Perspectives and concerns of the pastor's wife. Sexual Addiction \& Compulsivity, 10(2/3), 193-199. doi:1080/107201603902306307

Kraus, S. W., Voon, V., \& Potenza, M. N. (2016). Should compulsive sexual behavior be considered an addiction? Addiction, 111(12), 2097-2106. doi:10.1111/add.13297 
Larsen, E. (1987). Stage II relationship: Love beyond addiction. San Francisco, CA: Harper \& Row.

Liang, X. (2014). The estimation and specification search of structural equation modeling using frequentist and bayesian methods. (Doctor of Philosophy Doctoral Dissertation), Florida State University, Retrieved from http://diginole.lib.fsu.edu/islandora/object/fsu:254459/datastream/PDF/view

Lindley, N. R., \& Giordano, P. J. (1999). Codependency predictors and psychometric issues. Journal of Clinical Psychology, 55(1), 59-64.

Marks, A. D. G., Blore, R. L., Hine, D. W., \& Dear, G. E. (2012). Development and validation of a revised measure of codependency. Australian Journal of Psychology, 64(3), 119-127. doi:10.1111/j.1742-9536.2011.00034.X

Martin, P. R., \& Petry, N. M. (2005). Are non-substance-related addictions really addictions? The American Journal on Addiction, 14(1), 1-7. doi:10.1080/10550490590899808

Matheny, J. H. (1998). Strategies for assessment and early treatment with sexually addicted families. Sexual Addiction \& Compulsivity, 5(1), 27-48.

Milrad, R. (1999). Coaddictive recovery: Early recovery issues for spouses of sex addicts. Sexual Addiction \& Compulsivity, 6(2), 125-136.

Minwalla, O. (2011). What about me and my sexuality? In S. Carnes (Ed.), Mending a shattered heart: A guide for partners of sex addicts. Carefree, AZ: Gentle Path Press.

Minwalla, O. (2012, Jul 23). Partners of sex addicts need treatment for trauma. Retrieved from http://nationalpsychologist.com/2012/07/partners-of-sex-addicts-need-treatment-for-trau ma 
Minwalla, O. (2015, Mar 31). 'Sexual sobriety’ leaves victims untreated. Retrieved from http://nationalpsychologist.com/2015/03/sexual-sobriety-leaves-victims-untreated/10281 0. html

Minwalla, O. (n.d.). SAI trauma model. Retrieved from http://theinstituteforsexualhealth.com/about-us/sai-trauma-model/

Morgan, J., J. P. (1991). What is codependency? Journal of Clinical Psychology, 47(5), 720729.

Muthén, B. O. (2011, Mar 18). Correlation between factors. Retrieved from http://www.statmodel.com/discussion/messages/9/3192.html?1495586652

Muthén, L. K., \& Muthén, B. O. (2015a). Mplus (Version 7.4). Retrieved from http://www.statmodel.com

Muthén, L. K., \& Muthén, B. O. (2015b). Mplus user's guide (7th ed.). Los Angeles, CA: Muthén \& Muthén.

Panaghi, L., Ahmadabadi, Z., Khosravi, N., Sadeghi, M. S., \& Madanipour, A. (2016). Living with addicted men and codependency: The moderating effect of personality traits. Addiction and Health, 8(2), 98-106.

Pew Research Center. (2015, Nov 3). U.S. Public becoming less religious. Retrieved from http://www.pewforum.org/2015/11/03/u-s-public-becoming-less-religious/

Plant, M., \& Plant, M. (2009). Sex addiction: a comparison with dependence on psychoactive drugs. Journal of Substance Use, 8(4), 260-266. doi:10.1080/14659890310001636125

Prest, L. A., \& Protinsky, H. (1993). Family systems theory: A unifying framework for codependence. American Journal of Family Therapy, 21(4), 352-360. 
Reise, S. P. (2012). Invited paper: The rediscovery of bifactor measurement models. Multivariate Behav Res, 47(5), 667-696. doi:10.1080/00273171.2012.715555

Reise, S. P., Bonifay, W. E., \& Haviland, M. G. (2013). Scoring and modeling psychological measures in the presence of multidimensionality. Journal of Personality Assessment, 95(2), 129-140. doi:10.1080/00223891.2012.725437

Rodriguez, A., Reise, S. P., \& Haviland, M. G. (2016). Evaluating bifactor models: Calculating and interpreting statistical indices. Psychological Methods, 21(2), 137-150. doi: $10.1037 /$ met0000045

Sarkar, S., Mattoo, S. K., Basu, D., \& Gupta, J. (2013). Codependence in spouses of alcohol and opioid dependent men. International Journal of Culture and Mental Health, 8(1), 13-21. doi:10.1080/17542863.2013.868502

Schneider, J. P., Weiss, R., \& Samenow, C. (2012). Is it really cheating? Understanding the emotional reactions and clinical treatment of spouses and partners affected by cybersex infidelity. Sexual Addiction \& Compulsivity, 19(1-2), 123-139. doi:10.1080/10720162.2012.658344

Skinner, K. B. (2015, Aug 13). The lasting effects of sexual betrayal. Retrieved from https://www.psychologytoday.com/blog/inside-porn-addiction/201508/the-lasting-effects -sexual-betrayal

Springer, C. A., Britt, T. W., \& Schlenker, B. R. (1998). Codependency: Clarifying the construct. Journal Of Mental Health Counseling, 20(2), 141-158.

Stafford, L. L. (2001). Is codependency a meaningful concept? Issues in Mental Health Nursing, 22(3), 273-286. doi:10.1080/01612840121607 
Steffens, B. A. (2005). The effects of disclosure on wives of sexual addicts. (Doctoral Dissertation), Retrieved from https://search.proquest.com/docview/305353623?accountid=4488 ProQuest Dissertations \& Theses Global database.

Steffens, B. A., \& Rennie, R. L. (2006). The traumatic nature of disclosure for wives of sexual addicts. Sexual Addiction \& Compulsivity, 13(2-3), 247-267. doi:10.1080/10720160600870802

Stokes, S. S. (2017). An examination of the psychometric properties of the Trauma Inventory for Partners of Sex Addicts (TIPSA). (Doctoral Dissertation), Brigham Young University.

Subby, R. (1984). Inside the chemically dependent marriage: Denial and manipulation. In. In Codependency: An emerging issuse (pp. 25-29). Pampano Beach, FL: Health Communications.

Tabachnick, B. G., \& Fidell, L. S. (2007). Using multivariate statistics (5th ed.). Boston, MA: Pearson Education.

Tripodi, C. (2006). Long term treatment of partners of sex addicts: A multi-phase approach. Sexual Addiction \& Compulsivity, 13(2-3), 269-288. doi:10.1080/10720160600870810 Vohs, K. D., \& Baumeister, R. F. (2009). Addiction and free will. Addiction Research and Theory, 17(3), 231-235. doi:10.1080/16066350802567103

Wang, J., \& Wang, X. (2012). Structural equation modeling: Applications using Mplus: John Wiley \& Sons.

Weathers, F. W., \& Keane, T. M. (2007). The Criterion A problem revisited: controversies and challenges in defining and measuring psychological trauma. Journal of Trauma Stress, 20(2), 107-121. doi:10.1002/jts.20210 
Wegscheider-Cruse, S. (1985). Choicemaking. Pompano Beach, FL: Health Communications.

Wells, M. C., Hill, M. B., Brack, G., Brack, C. J., \& Firestone, E. E. (2006). Codependency's relationship to defining characteristics in college students. Journal of College Student Psychotherapy, 20(4), 71-84. doi:10.1300/J035v20n04_07

Whitfield, C. L. (1989). Co-dependence: Our most common addiction - some physical, mental, emotional, and spiritual perspectives. Alcoholism Treatment Quarterlly, 6, 19-36.

Yu, C. (2002). Evaluating cutoff criteria of model fit indices for latent variable models with binary and continuous outcomes (Doctoral Dissertation), Retrieved from https://www.statmodel.com/download/Yudissertation.pdf

Zitzman, S. T., \& Butler, M. H. (2009). Wives' experience of husbands' pornography use and concomitant deception as an attachment threat in the adult pair-bond relationship. Sexual Addiction \& Compulsivity, 16(3), 210-240. doi:10.1080/10720160903202679 


\section{APPENDIX A \\ Trauma Inventory for Partners of Sex Addicts (TIPSA)}

Adapted from Skinner, K. B. (2015). Trauma Inventory for Partners of Sex Addicts (TIPSA.V2.1) [Online survey]. Retrieved from https://www.surveymonkey.com/r/ptdb2015

\begin{tabular}{|c|c|c|c|c|c|}
\hline $\begin{array}{c}\text { Criteria A: } \\
\text { Exposed to Threat }\end{array}$ & $\frac{\sum_{2}^{\infty}}{2}$ & 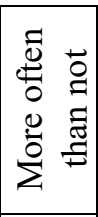 & 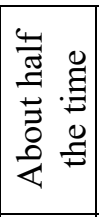 & 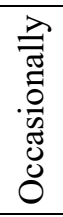 & $\begin{array}{l}\dot{0} \\
\dot{0} \\
z\end{array}$ \\
\hline $\begin{array}{l}\text { 1. I experience intense feelings of indescribable fear since discovering my } \\
\text { partner's sexual misbehaviors. }\end{array}$ & 5 & 4 & 3 & 2 & 1 \\
\hline 2. I have feelings of helplessness since discovering my partner's behaviors. & 5 & 4 & 3 & 2 & 1 \\
\hline $\begin{array}{l}\text { 3. My partner threatens to hurt me in some way if I do not comply with } \\
\text { his/her sexual fantasies. }\end{array}$ & 5 & 4 & 3 & 2 & 1 \\
\hline $\begin{array}{l}\text { 4. Due to my partner's sexual behaviors, I have become concerned that I } \\
\text { might contract a sexually transmitted disease. }\end{array}$ & 5 & 4 & 3 & 2 & 1 \\
\hline $\begin{array}{l}\text { 5. Since discovering my partner's behaviors, I have a hard time determining } \\
\text { who is safe to be around and who is not safe to be around. }\end{array}$ & 5 & 4 & 3 & 2 & 1 \\
\hline 6. I felt safe with my partner until I discovered his/her sexual behaviors. & 1 & 2 & 3 & 4 & 5 \\
\hline 7. I feel violated due to my partner's sexual behaviors. & 5 & 4 & 3 & 2 & 1 \\
\hline 8. I feel like my partner will never stop sexually acting out. & 5 & 4 & 3 & 2 & 1 \\
\hline $\begin{array}{l}\text { 9. Since learning of my partner's behaviors, my partner has hurt, hit, or } \\
\text { threatened me. }\end{array}$ & 5 & 4 & 3 & 2 & 1 \\
\hline 10. Since learning of my partner's behaviors, I feel afraid of my partner. & 5 & 4 & 3 & 2 & 1 \\
\hline $\begin{array}{l}\text { 11. My partner's behaviors remind me of experiences I had earlier in my } \\
\text { life. }\end{array}$ & 5 & 4 & 3 & 2 & 1 \\
\hline $\begin{array}{l}\text { Criteria B: } \\
\text { Reliving the Event }\end{array}$ & 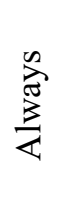 & 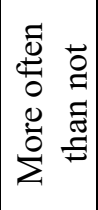 & 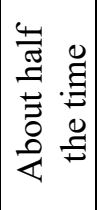 & 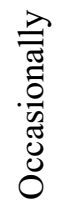 & 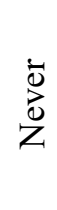 \\
\hline $\begin{array}{l}\text { 12. Since discovering my partner's behaviors, I can't look at him without } \\
\text { thinking about them. }\end{array}$ & 5 & 4 & 3 & 2 & 1 \\
\hline $\begin{array}{l}\text { 13. I have strong memories that remind me of my partner's participation in } \\
\text { sexually inappropriate behaviors. }\end{array}$ & 5 & 4 & 3 & 2 & 1 \\
\hline $\begin{array}{l}\text { 14. I have disturbing dreams that remind me of my partner's sexual } \\
\text { problems. }\end{array}$ & 5 & 4 & 3 & 2 & 1 \\
\hline $\begin{array}{l}\text { 15. When my partner tries to get close to me or we are sexually intimate I } \\
\text { cannot help but question whether my partner is thinking about me or things } \\
\text { he/she has done. }\end{array}$ & 5 & 4 & 3 & 2 & 1 \\
\hline
\end{tabular}




\begin{tabular}{|c|c|c|c|c|c|}
\hline $\begin{array}{l}\text { 16. I have episodes where I feel like I am reliving the event over and over } \\
\text { again. }\end{array}$ & 5 & 4 & 3 & 2 & 1 \\
\hline $\begin{array}{l}\text { 17. I have a hard time with media because so many things remind me of } \\
\text { what my partner has done. }\end{array}$ & 5 & 4 & 3 & 2 & 1 \\
\hline $\begin{array}{l}\text { 18. I have a hard time being in public places with my partner because I have } \\
\text { become highly sensitive to what my partner is looking at. }\end{array}$ & 5 & 4 & 3 & 2 & 1 \\
\hline $\begin{array}{l}\text { 19. Since discovering my partner's behavior, when I see sexually suggestive } \\
\text { images I feel anxious. }\end{array}$ & 5 & 4 & 3 & 2 & 1 \\
\hline $\begin{array}{l}\text { 20. If I am exposed to things that remind me of what my partner has done, I } \\
\text { suddenly become physically ill (i.e. nauseous, headaches, anxiety, vomit). }\end{array}$ & 5 & 4 & 3 & 2 & 1 \\
\hline 21. I struggle to think of other things besides what my partner has done. & 5 & 4 & 3 & 2 & 1 \\
\hline $\begin{array}{l}\text { Criteria C: } \\
\text { Avoidance }\end{array}$ & $\frac{\infty}{2}$ & 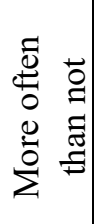 & 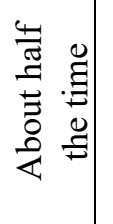 & 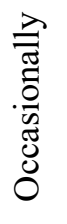 & $\frac{\overline{0}}{\grave{Z}}$ \\
\hline $\begin{array}{l}\text { 22. I spend a lot of energy trying to avoid thinking about my partner's } \\
\text { behaviors. }\end{array}$ & 5 & 4 & 3 & 2 & 1 \\
\hline $\begin{array}{l}\text { 23. I engage in behaviors that distract me (i.e., excessive reading, sleeping, } \\
\text { eating, drinking) from thinking about my partner's behavior. }\end{array}$ & 5 & 4 & 3 & 2 & 1 \\
\hline $\begin{array}{l}\text { 24. I avoid sexual contact with my partner since discovering his/her } \\
\text { behavior. }\end{array}$ & 5 & 4 & 3 & 2 & 1 \\
\hline $\begin{array}{l}\text { 27. I avoid going to places or locations where people could be dressed } \\
\text { scantily (e.g., mall, swimming pool, parks). }\end{array}$ & 5 & 4 & 3 & 2 & 1 \\
\hline 28. I intentionally plan activities to avoid being around my partner. & 5 & 4 & 3 & 2 & 1 \\
\hline $\begin{array}{l}\text { 29. It is hard for me to be around others when they say something positive } \\
\text { about their partner. }\end{array}$ & 5 & 4 & 3 & 2 & 1 \\
\hline $\begin{array}{l}\text { Criteria D: } \\
\text { Cognition and Negative Mood }\end{array}$ & $\begin{array}{l}\sum^{n} \\
\frac{\pi}{2} \\
\end{array}$ & 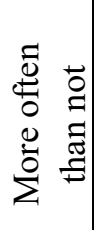 & 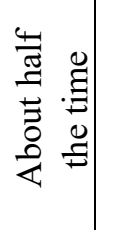 & 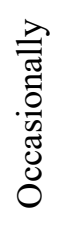 & $\begin{array}{l}\dot{0} \\
\dot{0} \\
\bar{Z}\end{array}$ \\
\hline 25. Since discovering my partner's behavior I get distracted easily. & 5 & 4 & 3 & 2 & 1 \\
\hline $\begin{array}{l}\text { 26. Since learning of my partners' behaviors, I have a hard time } \\
\text { participating in things that I previously enjoyed. }\end{array}$ & 5 & 4 & 3 & 2 & 1 \\
\hline 30. I feel like my partner acts out because I am not good enough. & 5 & 4 & 3 & 2 & 1 \\
\hline 31. I feel like it is my fault that my partner sexually acts out. & 5 & 4 & 3 & 2 & 1 \\
\hline 32. After what my partner has done I feel like it is hard to trust anyone. & 5 & 4 & 3 & 2 & 1 \\
\hline 33. I feel ashamed because of what my partner has done. & 5 & 4 & 3 & 2 & 1 \\
\hline
\end{tabular}




\begin{tabular}{|c|c|c|c|c|c|}
\hline $\begin{array}{l}\text { 34. Since I discovered my partner's behavior I hold back from people who } \\
\text { used to be close to me. }\end{array}$ & 5 & 4 & 3 & 2 & 1 \\
\hline 35. I am still able enjoy things since learning of my partner's behavior. & 1 & 2 & 3 & 4 & 5 \\
\hline 36. I feel like I am a bad person because of what my partner has done. & 5 & 4 & 3 & 2 & 1 \\
\hline 37. When I am in social settings I don't feel like I belong anymore. & 5 & 4 & 3 & 2 & 1 \\
\hline $\begin{array}{l}\text { 38. Since discovering my partner's behaviors, I feel like I am different than } \\
\text { everyone else. }\end{array}$ & 5 & 4 & 3 & 2 & 1 \\
\hline 39. I feel people, in general, are safe. & 1 & 2 & 3 & 4 & 5 \\
\hline 40. I feel like my spouse would not be this way if society was not so bad. & 5 & 4 & 3 & 2 & 1 \\
\hline $\begin{array}{l}\text { Criteria E: } \\
\text { Emotional Arousal }\end{array}$ & 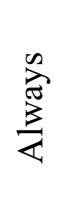 & 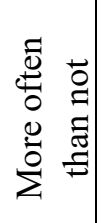 & 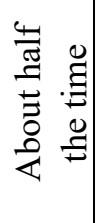 & 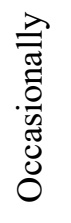 & $\dot{\bar{D}}$ \\
\hline 41. Since learning of my partner's behavior I have difficulty falling asleep & 5 & 4 & 3 & 2 & 1 \\
\hline $\begin{array}{l}\text { 42. After discovering my partner's sexual behaviors, I find that I am } \\
\text { increasingly angry in response to my partner. }\end{array}$ & 5 & 4 & 3 & 2 & 1 \\
\hline $\begin{array}{l}\text { 43. I find that I am more critical in conversations with my partner since } \\
\text { discovering his/her behavior. }\end{array}$ & 5 & 4 & 3 & 2 & 1 \\
\hline $\begin{array}{l}\text { 44. I feel like I am emotionally on edge more now than I used to be before } \\
\text { all this happened. }\end{array}$ & 5 & 4 & 3 & 2 & 1 \\
\hline 45. I have been surprisingly calm since discovering my partners' behaviors. & 1 & 2 & 3 & 4 & 5 \\
\hline $\begin{array}{l}\text { 46. I find it harder to focus on what is going on around me since I } \\
\text { discovered my partner's behavior. }\end{array}$ & 5 & 4 & 3 & 2 & 1 \\
\hline 47. I find that I lose things since I learned of my partner's behaviors. & 5 & 4 & 3 & 2 & 1 \\
\hline 48. I closely monitor my partner's behaviors. & 5 & 4 & 3 & 2 & 1 \\
\hline $\begin{array}{l}\text { 49. When I am around my partner, I am constantly trying to read his/her } \\
\text { emotions. }\end{array}$ & 5 & 4 & 3 & 2 & 1 \\
\hline 50. I feel like I need to check up on my partner. & 5 & 4 & 3 & 2 & 1 \\
\hline 51. I feel more anxious since I learned of my partner's behavior. & 5 & 4 & 3 & 2 & 1 \\
\hline 52. I feel suicidal due to this experience with my partner. & 5 & 4 & 3 & 2 & 1 \\
\hline 53. I am worried that I may follow through on an impulse to hurt myself. & 5 & 4 & 3 & 2 & 1 \\
\hline
\end{tabular}

